\title{
Urban Atmospheric Environmental Capacity and Atmospheric Environmental Carrying Capacity Constrained by GDP-PM 2.5
}

Yejing Zhou ${ }^{\text {a }}$ Jingxuan Zhou ${ }^{\mathrm{a}, *}$

\begin{abstract}
China faces a contradictory period of economic development and environmental protection, with it being essential to control total emissions within the limit of atmospheric environmental capacity (AEC) by promoting atmospheric environmental carrying capacity (AECC). This implies that well-calculated AEC and AECC values are the key macro-criteria for improving environmental quality and supporting the challenging coordinated development of economy and environment. When considering compound air pollution characterised as fine particulate matter $\left(\mathrm{PM}_{2.5}\right)$, conventional methods are not capable of calculating AEC and AECC, but the system dynamics (SD) method retains the advantage of simplicity in resolving complex problems. In the present study, we first describe the background and definitions of AEC and AECC, which are different from Western concepts, and their dialectical relationships. Then, with the statistical data from Wuhan city in 2014, we establish an 'economy-energy-atmospheric environment' dynamic model using the SD method, which does not need to simulate the complicated physicochemical processes of atmospheric transmission and diffusion. Instead, it uses the pollutants' proportionality factors and conversion rates to establish quantitative connections among different types of variables. Finally, we simulate the dynamic trends of gross domestic production (GDP), $\mathrm{PM}_{2.5}$, and six air pollutant emissions between 2015 and 2030 in four different scenarios and calculate the results of AEC and AECC constrained by GDP and $\mathrm{PM}_{2.5}$.
\end{abstract}

Keywords: GDP; $\mathrm{PM}_{2.5}$; Atmospheric environmental capacity; Atmospheric environmental carrying capacity; System dynamics; Wuhan city 
Huazhong University of Science and Technology (HUST), Hongshan District, Wuhan City, China E-mail addresses: zjxlypyj@163.com (Jingxuan Zhou), 476402115@qq.com (Yejing Zhou)

\section{Introduction}

China's rapid and extensive economic development over the past three decades has caused serious environmental pollution, with compound air pollution characterised as fine particulate matter $\left(\mathrm{PM}_{2.5}\right)$ being especially conspicuous in recent years. $\mathrm{PM}_{2.5}$ is the particulate matter floating in the air for an extended period whose diameter is less than $2.5 \mu \mathrm{m} . \mathrm{PM}_{2.5}$ is formed by a variety of air pollutants such as sulphur dioxide $\left(\mathrm{SO}_{2}\right)$, nitrogen oxides $\left(\mathrm{NO}_{\mathrm{x}}\right)$, non-methane volatile organic compounds (VOCs), ammonia $\left(\mathrm{NH}_{3}\right)$ and dust, thus severely affecting people's health and social and economic development (Pui et al., 2014; Kiesewetter et al., 2015; Oxley et al., 2015; Li et al., 2016). The Chinese government has implemented the Interim Targets 1 of the Air Quality Guidelines (the lowest) established by the World Health Organization (WHO) as the 'qualified' level of $\mathrm{PM}_{2.5}$ concentration according to the present conditions (WHO, 2005). In 2012, the new Chinese National Ambient Air Quality Standard (NAAQS) was amended and issued by the Ministry of Environmental Protection of China (MEP). In the NAAQS, the annual average $\mathrm{PM}_{2.5}$ concentration Grade II limit is $35 \mu \mathrm{g} / \mathrm{m}^{3}$, with the 24 -h average concentration Grade II limit being $75 \mu \mathrm{g} / \mathrm{m}^{3}$ (MEP, 2012).

Currently, in the background of the economic slowdown (called 'new normal' in China), the Chinese government would like to improve environmental quality and ensure a coordinated development of economy and environment through the utilisation of total emission control systems and environmental quality control systems (Zhang et al., 2013; Zhang et al., 2014). Essentially, the calculation of environmental capacity is the key connection between these two systems. In 2015, an important document, the Integrated Reform Plan for Promoting Ecological Progress, issued by the Communist Party of China Central Committee and the State Council emphasised that regional development must be constrained within its environmental capacity and that the use of the restricted environmental carrying capacity supports greater social and economic development for the future. This implies that a well-calculated atmospheric environmental capacity (AEC) and atmospheric environmental carrying capacity (AECC) establish the 
1 foundation for controlling total emissions, improving environmental quality and guaranteeing coordinated economic development (Wang et al., 2015; Zhang and Hao, 2016).

However, the current calculations of AEC and AECC have some complications. On the one hand, a minority of government administrators still consider gross domestic production (GDP) growth to be more important and ignore environmental protection. The environment-related statistical and monitoring data are usually inaccessible and some historical data may be missing. Moreover, no effective laws demand that mandatory information be made public, which results in difficulty in analysing AEC and AECC. On the other hand, some environmental scholars regard the AEC and AECC analysis as technically cumbersome because the traditional physicochemical methods are not suitable for calculating AEC characterised as compound air pollution. For example, the A-P value method, a widely used AEC calculation method in China, is apt only for the determination of air pollutants produced by burnt coal and is not suitable for compound pollutants. The third-generation air quality models such as the Community Multiscale Air Quality model are widely used by weather departments and are a tool for early warning forecast of air quality. These models can also be used to predict the short-term AEC characterised as $\mathrm{PM}_{2.5}$, however, they are not suitable for long-term predictions, which require a large quantity of data such as emission source data and meteorological data and a large amount of computer processing (Xue et al., 2013; Djalalova et al., 2015; Zhang et al., 2016). Moreover, timely control of air pollutant emissions after early warning signals and forecasting is not enough. Annual average $\mathrm{PM}_{2.5}$ concentrations, not daily concentrations, are preferable as the first consideration when measuring the regional long-term air quality. The AEC and AECC calculations that are constrained by GDP and $\mathrm{PM}_{2.5}$ are a complicated systematic problem that needs to be analysed so that it considers all aspects of the complex system, such as reference to economy, society, energy use and the environment. When dealing with complex systems, physicochemical methods have an inevitable disadvantage, namely that the economic and social systems cannot be integrated into an environmental model (Vafa-Arani et al., 2014), and these methods are unable to calculate AECC thresholds. Therefore, a system dynamics (SD) method is an appropriate approach for the study of complex systems, because it retains the advantage of simplicity in resolving complex problems 
To date, in the literature, we have not found any explicit calculations for the annual regional AEC and AECC thresholds constrained by $\mathrm{PM}_{2.5}$ using the SD method (Feng et al., 2013; McKnight and Finkel, 2013; Chateau et al., 2015; Gao et al., 2016; Sahin et al., 2016). In 2014, we created an 'economy-atmospheric environment' dynamic model for the 'Pollution Characteristics and Prevention Counter Measures of $\mathrm{PM}_{2.5}$ ' project in Dongguan City, Guangdong province. The predicted results had a well-guiding significance, concluding with a good evaluation. Appointed by the Wuhan Environment Protection Science Research Institute (WEPSRI) in 2015, we commenced a study of AEC and AECC analysis for Wuhan city. Compared with Dongguan, Wuhan city has a larger geographical area, greater population and more complicated circumstances. The subsystems of economy and atmospheric environment in the model for this city were improved, and an energy subsystem was added to the SD model. By adjusting the energy consumption and industrial growth rates, the development of industry and energy can be directly predicted. Improvements made to the model optimised the operability of the model, i.e. the readability of the AEC and AECC thresholds. This shows that adjusting the structure of industry and energy plays an important role in improving environmental quality.

In the present study, we clarify the definitions of AEC, atmospheric environmental stress (AES) and AECC, expand the concept of AECC and describe its dialectical relationship that is constrained by GDP and $\mathrm{PM}_{2.5}$. We also establish an 'economy-energy-atmospheric environment' dynamic model using the SD method based on the data of Wuhan city's economical, meteorological, energy and environmental statistical data in 2014. An SD model does not require simulation of the complicated physicochemical processes of atmospheric transmission and diffusion; instead it exploits the pollutants' proportionality factors and conversion rates to establish quantitative connections among different kinds of variables such as GDP, annual $\mathrm{PM}_{2.5}$ concentration and six air pollutant emissions $\left(\mathrm{SO}_{2}, \mathrm{NO}_{x}, \mathrm{VOCs}, \mathrm{NH}_{3}\right.$, primary $\mathrm{PM}_{10}$ and primary $\mathrm{PM}_{2.5}$ ). Assuming a stable climatic environment over the next several years, changing the control variables of economy, energy and emission reduction enables us to forecast GDP, pollutant emissions and annual concentrations of $\mathrm{PM}_{2.5}$ and $\mathrm{PM}_{10}$ from the year 2015 to 2030 in four scenarios. This was then used to calculate AEC and AECC thresholds $\left(\mathrm{PM}_{10}\right.$ is also particulate matter whose diameter is less than $10 \mu \mathrm{m}$ and having a tight relationship with $\mathrm{PM}_{2.5}$ ). 


\section{Background, concepts and technology roadmap}

The concepts of environmental capacity and environmental carrying capacity are different between Western countries and China; because different countries are at different stages in their environmental protection plans. Developed countries have progressed from the contradictory period of economic development and environmental protection towards a period that contains environmental quality protection. These countries have no need for a considerable emission reduction scheme and maintain their environmental status through supervision and regulation. With reference to the two concepts of environmental capacity and environmental carrying capacity, the majority of researchers from Western countries do not differentiate between them. Instead, they generally study the capacity of ecological and urban resources from the perspective of the ecological or environmental system itself, such as forests, land use, marine, mineral and transportation capacity (Zeng et al., 1991; Arrow et al., 1995; Saveriades, 2000; Furuya, 2004;

\section{Mondino et al., 2014; Martire et al., 2015).}

However, these two concepts in China are very different. Several Chinese researchers study them from the perspective of environmental carrying variables such as social, economic, technological development and the accompanying pollution. Developing countries, including China, are still located in the climb portion of the Environment-Economy Kuznets curve ('Inverted-U' curve), where a number of environmental indicators fail to reach the established standards. It is therefore necessary to distinguish the bottom line that the environment can bear, i.e. the environmental capacity, as well as determine the scale of social and economic activities within a reasonable scope of lower effect to the environmental quality, i.e. environmental carrying capacity, for China and other developing countries. Additionally, the Chinese government has powerful macro-control, and is capable of regulating the social and economic activity to ensure better development.

Thus, environmental capacity is generally defined as the maximum total pollutant load that the environment can receive according to the environmental quality standard in a certain geographical range. This is a prototype of the concept of environmental carrying capacity theory (Wang et al., 2005; Li, 2007). However, environmental issues are complex, and have close relationships with 
social and economic development. This means that merely discussing the assimilative capacity of the environment itself cannot meet China's future developmental needs. Conceptually, on the basis of the environmental capacity, the environmental carrying capacity needs to be extended to include not only capacity, but also the scale of human activities. The environmental carrying capacity refers to the appropriate thresholds of the environmental system that support human activity in maintaining the environmental system structure without qualitative change, the environment function without destruction within a certain geographical area and over a certain period.( Ye et al., 1992; Zeng et al., 1998; Liu et al., 2009). In the present study, the concepts of AEC, AES and AECC are described as follows.

\subsection{Atmospheric Environmental Capacity (AEC)}

AEC is the maximum allowable quantity of pollutant emissions when an air pollutant's concentration is no greater than its environmental target in an area's atmospheric environment, and is an important component of AECC. In the present study, AEC refers to the maximum allowable discharged volume of certain air pollutants, including $\mathrm{SO}_{2}, \mathrm{NO}_{\mathrm{x}}$, VOC, $\mathrm{NH}_{3}$, primary $\mathrm{PM}_{2.5}$ and primary $\mathrm{PM}_{10}$, when $\mathrm{PM}_{2.5}$ concentration reaches Grade II of NAAQS (average annual limit of 35 $\left.\mu \mathrm{g} / \mathrm{m}^{3}\right)$.

\subsection{Atmospheric Environmental Stress (AES)}

AES is the produced volume of atmospheric pollutants owing to human social and economic activities. The produced volume includes the discharged and reduced volume. AES in the present study is defined as the predicted discharged volume of six air pollutants according to the pollutants' discharged volumes, concentrations, emission inventories and sources apportionment in Wuhan city in 2014, on the premise of maintaining the current level of economy, energy and environmental protection and ensuring the standard growth of GDP.

\subsection{Atmospheric Environmental Carrying Capacity (AECC)}

In our definition, AECC is composed of two sections: 'recessive' and 'expressive' indicators. The 'recessive' component is the actual ability for maintaining environmental quality such as a regional economic state, industrial structure, energy structure, technological level, natural resources, geographical and meteorological factors, investments of environmental protection or 
other factors (Wang and Xu, 2015). The 'expressive' component is the external comprehensive performance of the 'recessive' portion. It is the accumulative reduced discharged volume shown as the sum of the stock and increment that counteracts a part of AES (see Fig. 1). In the present study, AECC explicitly refers to eight recessive indicators, namely a city's GDP; its production value of primary, secondary and tertiary industries, and the consumption of coal, petroleum, natural gas and new energy; and six expressive indicators, i.e. six air pollutants' accumulative reduced volume, namely $\mathrm{SO}_{2}, \mathrm{NO}_{\mathrm{x}}, \mathrm{VOC}, \mathrm{NH}_{3}$, primary $\mathrm{PM}_{2.5}$ and primary $\mathrm{PM}_{10}$.

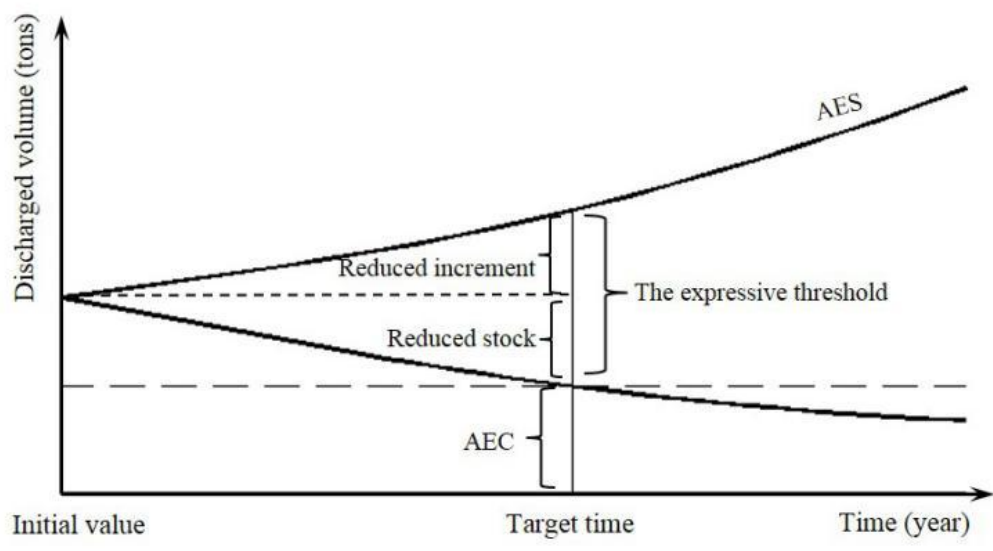

Fig.1 An illustrated explanation for the expressive component of AECC.

We chose these indicators for the following reasons. First, to ensure coordinated economic and environmental development, adjusting the energy and economic structure has great significance in improving the environmental quality, which concerns the government the most. Using the eight recessive indicators in the SD model can reflect this change. The recessive indicators also include variables such as population, but these contribute little to this research. Different researchers are able to use other indicators as they require them. Second, the more variables embedded into the model, the more complicated is the SD model. Additional variables need to establish dynamic quantitative relationships with the main variables such as GDP and $\mathrm{PM}_{2.5}$, which need more statistical data to support the SD model building.

Figure 2 shows the dynamic dialectical relationships between AEC, AES and AECC. In the first scenario (Fig. 2a), when a traditional GDP growth mode is based on fossil fuel use, AECC is always less than AES and the air pollution (Combined curve) is over AEC, which leads to the deterioration in environmental quality. In the second scenario (Fig. 2b), where AECC is eventually greater than AES, the air pollution (Combined curve) converges to AEC, which leads to the 


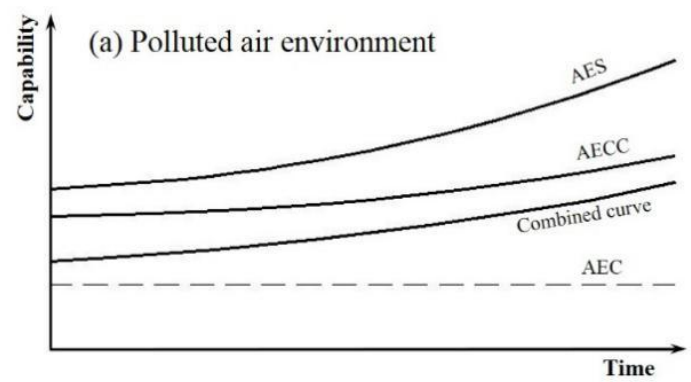
Wang et al, 2010; Zhang and Hao, 2016).

improvement in the environmental quality (Zeng et al,1991; Zeng et al, 1998; Liu et al, 2009;

4 Fig.2 Dialectical relationships of AES, AEC and AECC illustrated in two scenarios. The 'Combined curve', which could be regarded as the annual $\mathrm{PM}_{2.5}$ concentration, is a synthetic result of AECC's expressive component and AES.

7

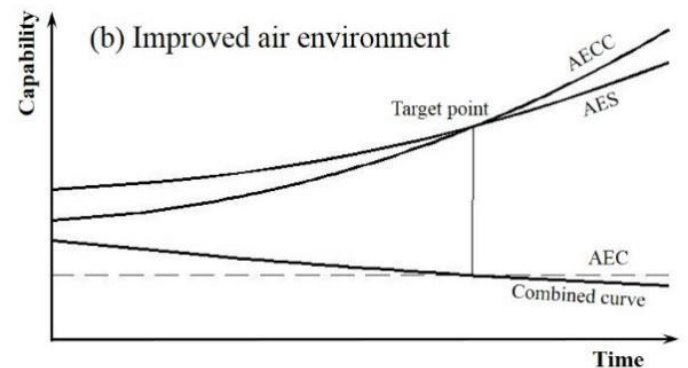

\subsection{Technology roadmap}

The following are the steps taken in the present study to build and study the SD model.

1) Focus on the research targets, i.e. the AEC and AECC, when confronting a complex objective;

2) Establish the indicators of targets to be investigated;

3) Confirm the SD model border;

4) Describe the causality of the SD model system;

5) Build the SD model flow diagram and test its usability;

6) Obtain the economy, meteorology, energy and the source apportionment (air pollution emission inventory) data;

7) Determine the SD model's parameters and write the model's equations;

8) Conduct the SD model check and reality test;

9) Allocate four scenarios - S1 Basic, S2 Moderate, S3 Enhanced and S4 Intense. The parameters in the four scenarios are in accordance with the requirements of WEPSRI. The specific parameter adjustment values of the economy, energy and environment in the SD model are given in Section 4.4

10) Predict Wuhan city's GDP, the annual concentrations of $\mathrm{PM}_{2.5}$ and $\mathrm{PM}_{10}$, and the changes in six pollutant emissions in the four scenarios;

11) Predict the AEC and AECC thresholds when the annual $\mathrm{PM}_{2.5}$ concentration reaches Grade II of NAAQS $\left(35 \mu \mathrm{g} / \mathrm{m}^{3}\right)$. The main progression of the research in the present study is illustrated in 


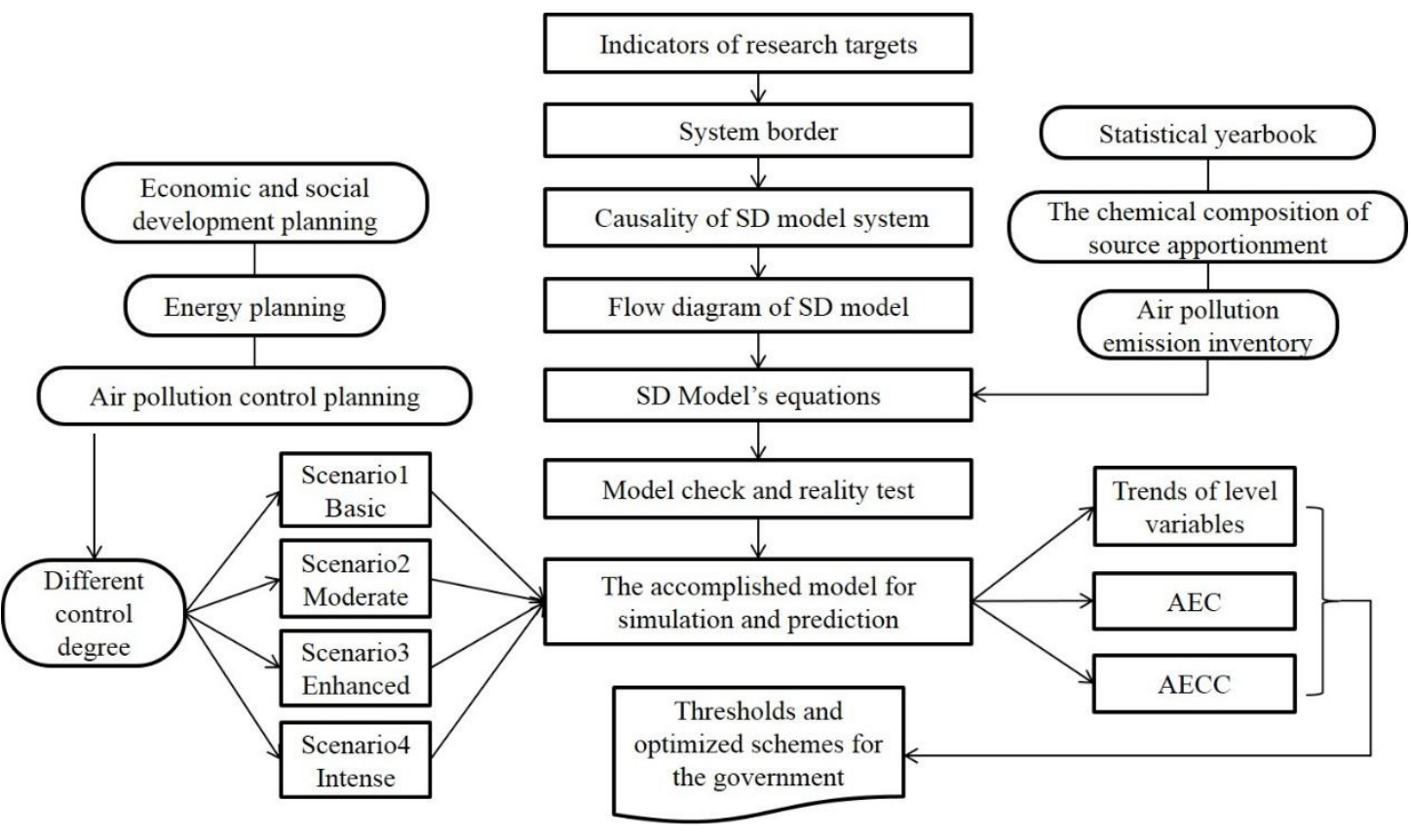

Fig.3 Technology roadmap in the AEC and AECC research

\section{Building the SD model}

\subsection{Causal description of the SD model system}

The entire SD model system is divided into energy, economic and environmental subsystems. The basic causal relationships in each subsystem are as follows:

1) From an energy point of view, in the traditional developmental mode, economic growth will lead to increased fossil fuel energy use, resulting in increased air pollutant emissions and greater annual average $\mathrm{PM}_{2.5}$ concentrations (Zhang et al, 2013; Wang et al, 2015; Chen et al, 2016). However, to protect the environment, people will limit polluting energy consumption, including the use of coal, petroleum and so on, which also limits the traditional economic development based on the consumption of fossil energy, characterised as an 'environment $\rightarrow$ energy $\rightarrow$ economy' restraining pollution process.

2) From an economic point of view, the deterioration in the environment confines the growth of the polluting industry; instead new service industries grow, which will control the pollution of the environment, characterised as an 'environment $\rightarrow$ economy $\rightarrow$ environment' restraining pollution process. 
13 ) From an environmental point of view, the end-treatment mode reduces emissions resulting in

2 pollution abatement.

3 The SD model focuses on the causality of restraining the pollution process. The above 4 relationships are illustrated in Figure 4.

5

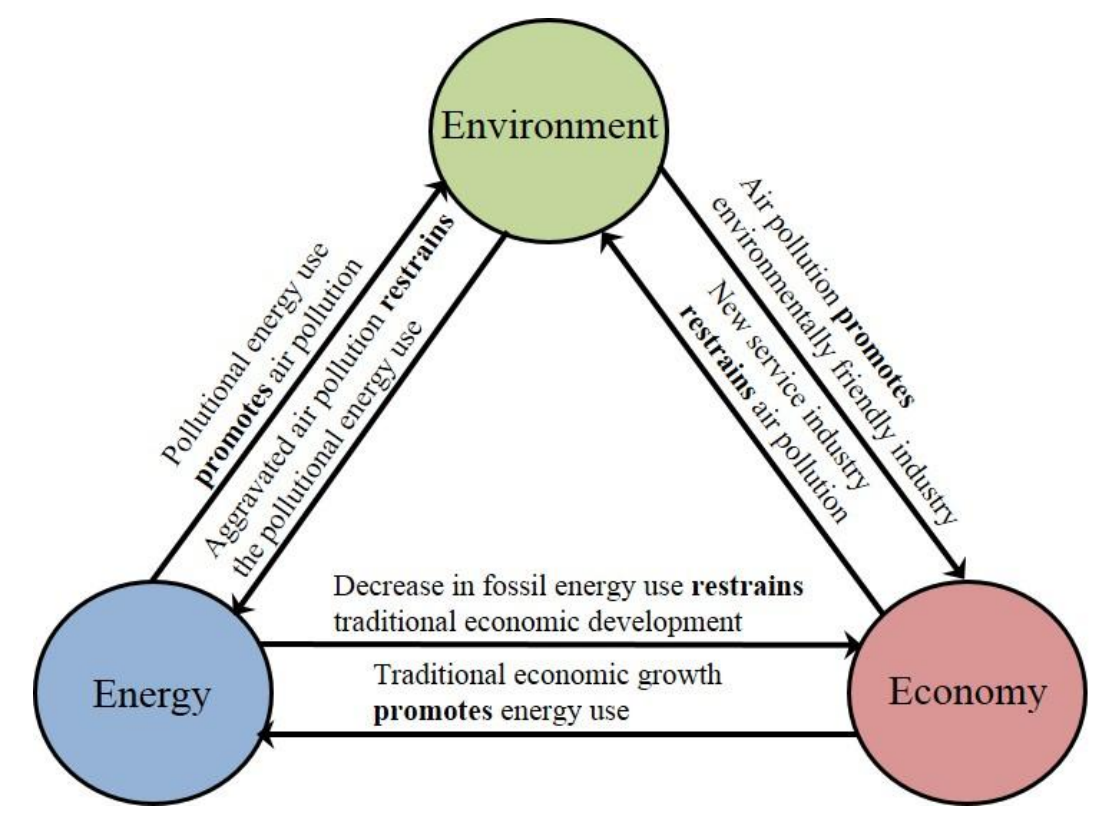

Fig.4 Description of cause and effect in three subsystems

\subsection{Variables of the SD model}

Each subsystem of the SD model consists of a series of variables, which can be divided into five types characterised by function, i.e. variables of level, rate, auxiliary, constant and control.

The classification of all the SD model variables is listed in Table 1.

\begin{tabular}{|c|c|c|c|c|c|}
\hline Subsystems & Level variables & Rate variables & Auxiliary variables & Constant variables & Control variables \\
\hline Environment & $\begin{array}{l}\text { Discharged volume of } \\
\text { VOC, } \mathrm{SO}_{2}, \quad \mathrm{NO}_{\mathrm{x}} \text {, } \\
\mathrm{NH}_{3} \text {, primary } \mathrm{PM}_{2.5} \\
\text { and primary } \mathrm{PM}_{10} \text {; } \\
\text { Annual concentration } \\
\text { of } \mathrm{PM}_{2.5} \text { and } \mathrm{PM}_{10} \text {, }\end{array}$ & $\begin{array}{l}\text { Increment in } \mathrm{VOC} \text {, } \\
\mathrm{NO}_{x}, \mathrm{SO}_{2}, \mathrm{NH}_{3} \text {, primary } \\
\mathrm{PM}_{2.5} \text {, primary } \mathrm{PM}_{10} \text {, } \\
\mathrm{PM}_{2.5} \text { and } \mathrm{PM}_{10} \text {; } \\
\text { Decrement in } \mathrm{VOC} \text {, } \\
\mathrm{SO}_{2} \text {, } \mathrm{NOx}, \quad \mathrm{NH}_{3}, \\
\text { primary } \mathrm{PM}_{2.5} \text {, primary } \\
\mathrm{PM}_{10}, \mathrm{PM}_{2.5} \text { and } \mathrm{PM}_{10}\end{array}$ & $\begin{array}{l}\text { <Time>, Proportionality factor of } \mathrm{SO}_{2} \text {, } \\
\mathrm{NO}_{x} \text {, VOC, } \mathrm{NH}_{3} \text {, primary } \mathrm{PM}_{10} \text { and } \\
\text { primary } \mathrm{PM}_{2.5} \text {, Conversion rate } \mathrm{SO}_{2}-\mathrm{PM}_{2.5} \text {, } \\
\mathrm{NO}_{x}-\mathrm{PM}_{2.5} \text {, VOC-PM } \mathrm{PM}_{2.5}, \mathrm{NH}_{3}-\mathrm{PM}_{2.5} \text {, } \\
\text { primary } \mathrm{PM}_{10} \text {, primary } \mathrm{PM}_{2.5} \text { and } \mathrm{PM}_{2.5} \\
\text { volume; } \\
\text { Conversion rate } \mathrm{SO}_{2}-\mathrm{PM}_{10}, \mathrm{NO}_{x}-\mathrm{PM}_{10} \text {, } \\
\text { VOC-PM } \mathrm{NH}_{10} \text {, } \mathrm{PM}_{10} \text { and City volume } \\
\text { under boundary layer }\end{array}$ & $\begin{array}{l}\text { Contribution rate } \mathrm{SO}_{2} \text { for } \\
\mathrm{PM}_{2.5}, \mathrm{NO}_{x} \text { for } \mathrm{PM}_{2.5} \text {, VOC } \\
\text { for } \mathrm{PM}_{2.5} \text { and } \mathrm{NH}_{3} \text { for } \mathrm{PM}_{2.5} \\
\text { and primary } \mathrm{PM}_{2.5} \text {; } \\
\text { Contribution rate } \mathrm{SO}_{2} \text { for } \\
\mathrm{PM}_{10}, \mathrm{NO}_{x} \text { for } \mathrm{PM}_{10} \text {, VOC } \\
\text { for } \mathrm{PM}_{10}, \mathrm{NH}_{3} \text { for } \mathrm{PM}_{10} \text { and } \\
\text { primary } \mathrm{PM}_{10} \text {, City area and } \\
\text { Height of boundary layer }\end{array}$ & $\begin{array}{l}\text { Emission } \\
\text { reduction factor } \\
\text { of } \mathrm{SO}_{2}, \mathrm{NO}_{x} \text {, } \\
\text { VOC, } \mathrm{NH}_{3} \text {, } \\
\text { primary } \mathrm{PM}_{10} \\
\text { and primary } \\
\mathrm{PM}_{2.5}\end{array}$ \\
\hline Energy & Annual consumption & Increment & $\begin{array}{l}\text { Time>, Energy growth rate, Energy } \\
\end{array}$ & consumption & Growth rate of \\
\hline
\end{tabular}




\begin{tabular}{|c|c|c|c|c|c|}
\hline & $\begin{array}{l}\text { of coal, natural gas, } \\
\text { petroleum and new } \\
\text { energy }\end{array}$ & $\begin{array}{l}\text { natural gas, petroleum } \\
\text { and new energy }\end{array}$ & $\begin{array}{l}\text { adjustment factor of } \mathrm{SO}_{2}, \mathrm{NOx} \text {, primary } \\
\mathrm{PM}_{2.5} \text {, primary } \mathrm{PM}_{10} \text { and } \mathrm{VOC} \text {; } \\
\text { Growth rate of } \mathrm{NOx} \text {, particulate matter, } \\
\text { Energy consumption of discharging NOx } \\
\text { and discharging particulate matter }\end{array}$ & elasticity coefficient & $\begin{array}{l}\text { coal, natural gas, } \\
\text { petroleum and } \\
\text { new energy }\end{array}$ \\
\hline Economy & $\begin{array}{l}\text { GDP of primary, } \\
\text { secondary and tertiary } \\
\text { industries }\end{array}$ & $\begin{array}{l}\text { Increment in primary, } \\
\text { secondary and tertiary } \\
\text { industries }\end{array}$ & $\begin{array}{l}\text { <Time>, GDP, polluting GDP, increment of } \\
\text { polluting GDP and growth rate of GDP }\end{array}$ & None & $\begin{array}{l}\text { Growth rate of } \\
\text { primary, } \\
\text { secondary and } \\
\text { tertiary industries }\end{array}$ \\
\hline
\end{tabular}

\section{$2 \quad 3.3$ Flow diagram of the SD model}

3 The flow diagram of the SD model describes a precise state of the entire system. We can

4 simulate and predict economic, energy and environmental trends and indicators of AEC and

5 AECC after creating the SD model, by setting each variable's parameters and equations in the

6 model. Apart from the control and constant variables, all other variable values are dynamically

7 changing throughout the operation of the SD model. Vensim PLE software provides SD modelling

8 and simulation capabilities (Yeh et al., 2006; Mao et al., 2013). The most essential mathematical

9 description of the SD model is given in the following equation (Wang, 2009):

$$
l v . S(t)=S\left(t_{0}\right)+\int_{t_{0}}^{t} \text { rate. } S(\mathrm{t}) \mathrm{dt}=S\left(t_{0}\right)+\int_{t_{0}}^{t}[\text { inflow } . \mathrm{S}(\mathrm{t})-\text { outflow } . \mathrm{S}(\mathrm{t})] \mathrm{dt}
$$

where $l v . S(t)$ (level variables) is the state of a level variable at (t) moment; $S\left(t_{0}\right)$ is this level variable's initial value; and the 'rate' in $\int^{t}$ rate.S(t)dt is the rate variables, describing the rate's accumulation from time $t_{0}$ to $t$.

The entire system diagram (Fig. 5) is too large to display on one page, instead, three subsystems are shown, namely the environmental subsystem (Fig. 5a), the energy subsystem (Fig. 5b) and the economic subsystem (Fig. 5c), which are not independent and have tight connection with each other. Detailed equations of the SD model system are given in the Appendix. 
(a) Environmental subsystem

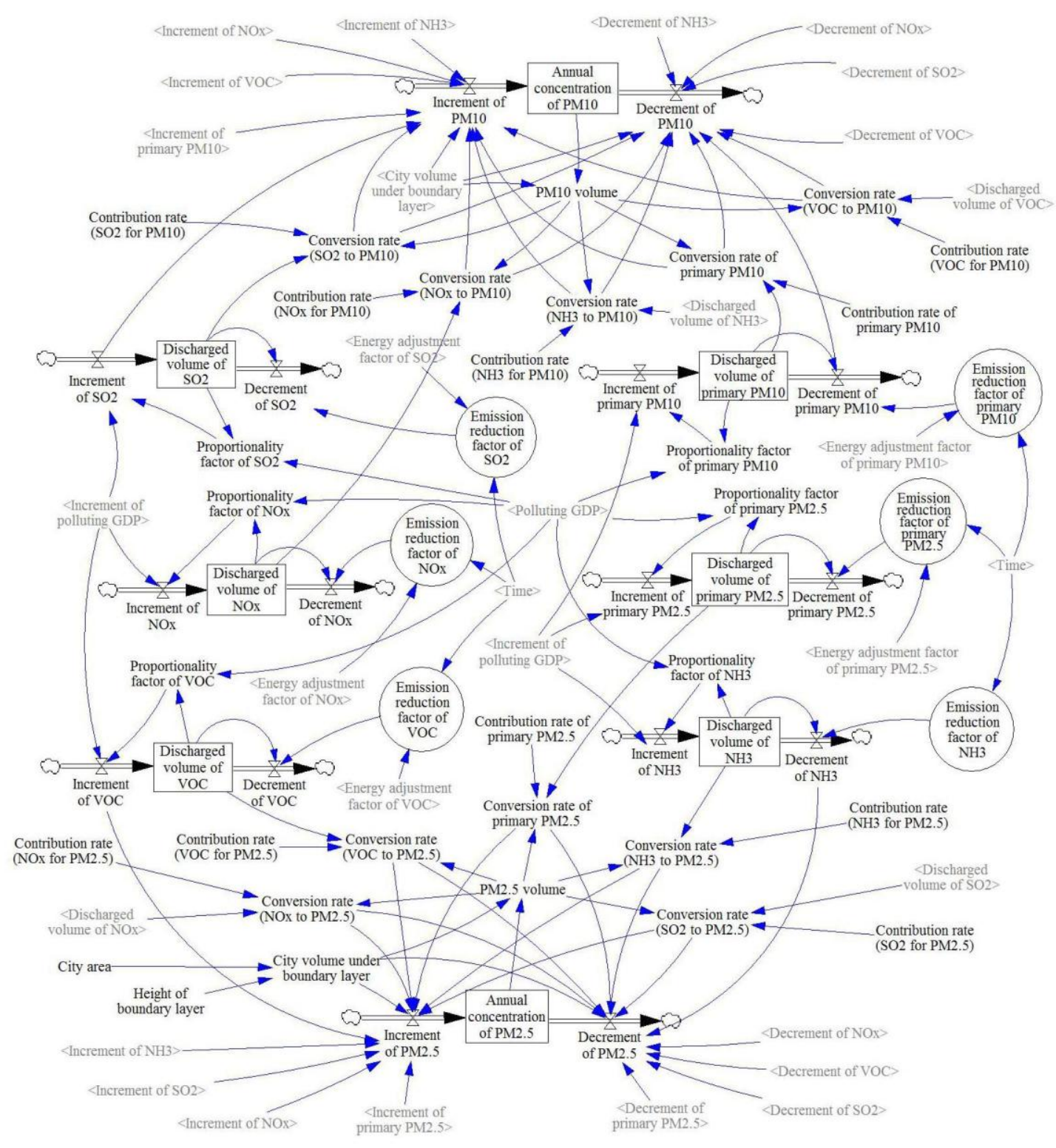


(b) Energy subsystem

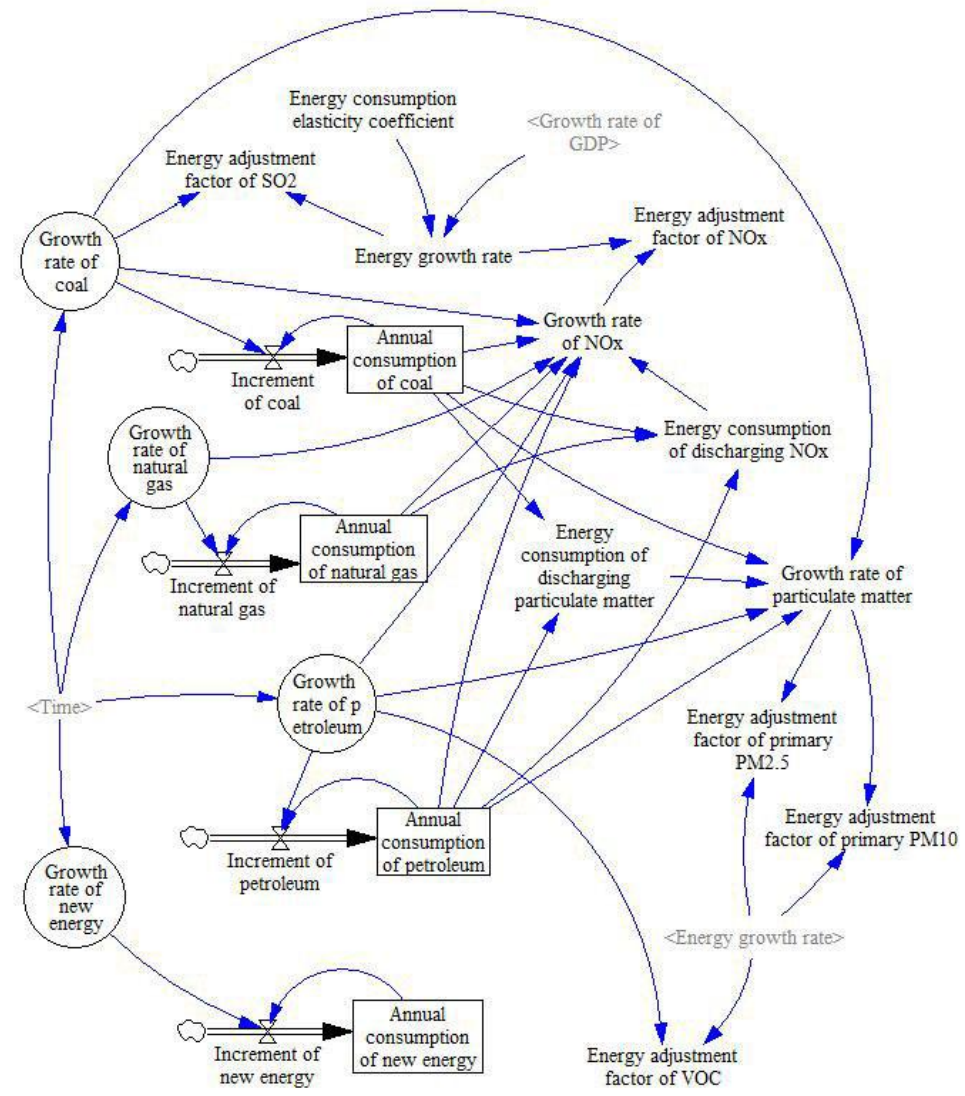

(c) Economic subsystem
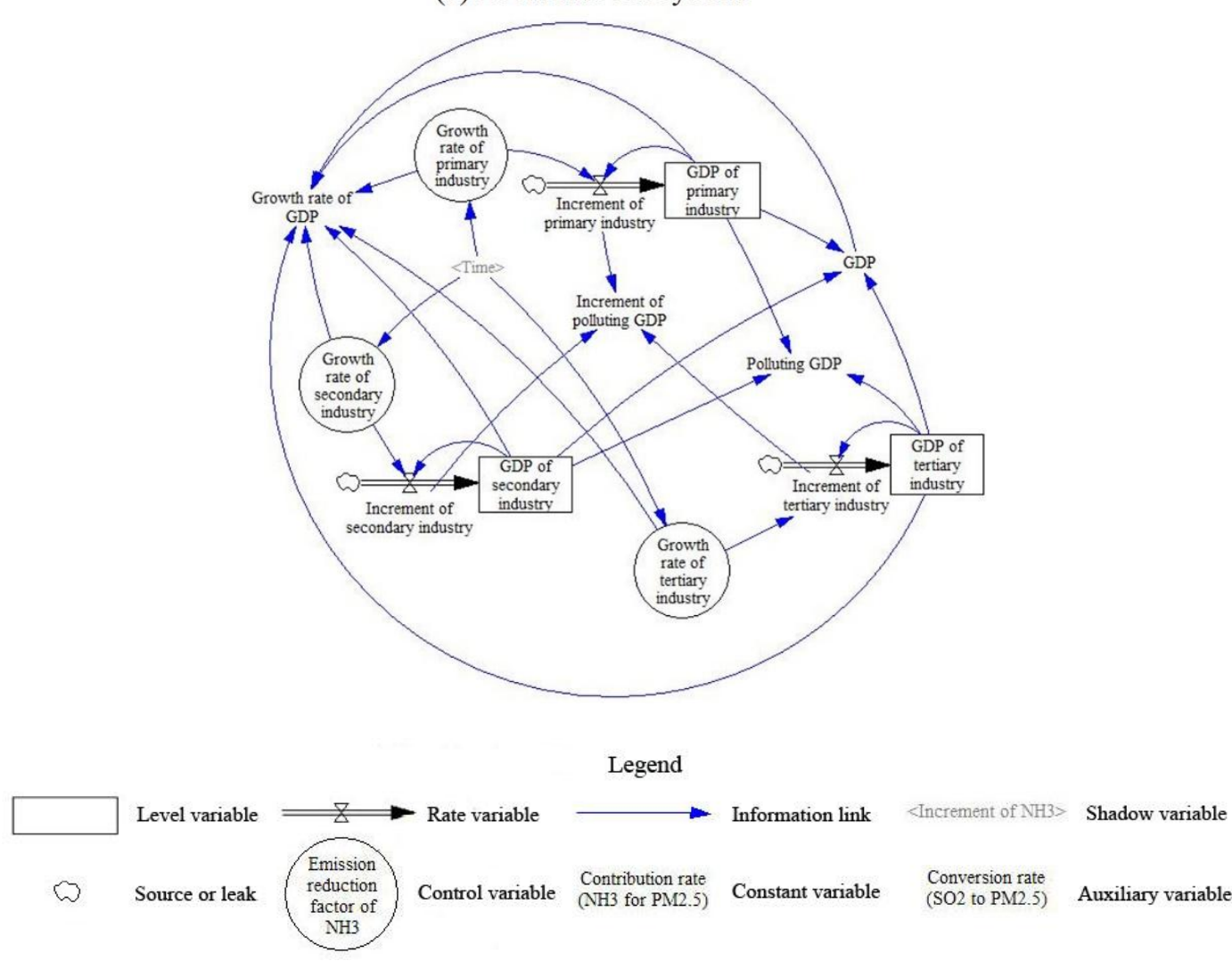

3

Fig. 5 Flow diagram of the SD model 
The basic simulating logical process of the SD model is that according to the requirement of a region's GDP growth rate, GDP growth promotes the increment of a certain pollutant-discharged

4 volume through the dynamic proportionality factor in the SD model. Next, the increment in a

5 certain pollutant's discharged volume makes the annual $\mathrm{PM}_{2.5}$ concentration increase by the variable of a pollutant's conversion rate, which is a link for connecting discharged volumes to

7 concentrations.

There are three specific control measures in the model to reduce emissions and improve environmental quality by simulating the variation trend of GDP, the concentration of $\mathrm{PM}_{2.5}$ and discharged volumes: (1) the changed proportion of pollution GDP through adjusting the growth rates of primary, secondary and tertiary industries shows the optimisation of industrial structure; (2) the reduced pollution increment per unit of GDP through adjusting different energy consumption growth rates portrays the optimisation of energy structure; and (3) the pollution end-treatment is realised by the emission reduction factors.

\subsection{Explanation of important variables}

1) The proportionality factor- $-\mu$

The proportionality factor, $\mu$, is a specific air pollutant discharged volume per billion Yuan of GDP. Its function is to convert the increment of GDP to the increment of a discharged volume quantitatively in a SD model dynamic simulation. The mathematical expression for $\mu$ is given as Equation (1). Its physical meaning can be regarded as an enterprise referred limit emissions per unit of GDP:

$$
\mu=\mathrm{Dv}_{i} / \mathrm{GDP}
$$

where Dv is the discharged volume (t); $i$ is a specific air pollutant; and GDP is a region's gross domestic production (billion Yuan).

2) The annual average height of the atmospheric boundary layer- $h$

The atmospheric boundary layer, a meteorological term, is an atmospheric layer that is affected by diurnal heat, moisture or momentum transfer to or from the surface in the troposphere, 
usually maintaining a $1-1.5 \mathrm{~km}$ thickness from the ground. Like a 'hat' covering a city, the $\mathrm{PM}_{2.5}$ usually exists under the boundary layer. During different periods and under different meteorological conditions the height of the boundary layer changes. Generally, the maximum diurnal height of the mixed layer is at $1500 \mathrm{~m}$ or greater, and the nocturnal stable boundary layer stays at $100 \mathrm{~m}$ (Hu et al., 2014).

\section{3) The $\mathrm{PM}_{2.5}$ volumeV.PM 2.5}

The $\mathrm{PM}_{2.5}$ volume is described as an annual average state that is a precise total mass of $\mathrm{PM}_{2.5}$ existing in a city space. The mathematical expression for V.PM 2.5 is given as Equation (2):

$$
\text { V.PM } 2.5=\mathrm{C} \mathrm{PM}_{2.5} \times \mathrm{S} \times h
$$

where C.PM 2.5 is the annual concentration of $\mathrm{PM}_{2.5}\left(\mu \mathrm{g} / \mathrm{m}^{3}\right)$; $\mathrm{S}$ is a city's administrative area $\left(\mathrm{km}^{2}\right)$ and $h$ is the annual average height of the atmospheric boundary layer.

In Equation (2), the annual concentration of $\mathrm{PM}_{2.5}$ is equal to its concentration at a previous time, adding the increment in the $\mathrm{PM}_{2.5}$ concentration to this time difference. The calculation method for the volume of $\mathrm{PM}_{10}$ is the same as for the $\mathrm{PM}_{2.5}$ volume.

4) The contribution rate of a certain air pollutant to $\mathrm{PM}_{2.5}$ or $\mathrm{PM}_{10}-\theta$

The contribution rate, $\theta$, is the proportion of chemical composition in source apportionment of $\mathrm{PM}_{2.5}$ or $\mathrm{PM}_{10}$. According to the general features of atmospheric particulate matter, sulphate comes from the transform contribution of $\mathrm{SO}_{2}$. This means that the contribution rate of $\mathrm{SO}_{2}$ in the model is approximately equal to the chemical composition proportion of sulphate, which is the same for nitrate and ammonium salts. Non-methane VOCs are relatively complex, but the majority of the organic matter $(\mathrm{OM})$ in the chemical composition proportion is from the transition of VOCs. In the present study, we set the contribution rate of VOC to be equivalent to the OM's proportion for convenience. The primary particulate matter's constitution is also complex, usually including black carbon, metal particles, mineral substances and so on (Huang et al, 2014; Yao et al., 2016; Zhou et al., 2016). Therefore, the contribution rate of primary particulate matter is equal to the sum of these substances' chemical composition proportions. 
1 5) The conversion rate from a certain air pollutant to $\mathrm{PM}_{2.5}$ or $\mathrm{PM}_{10}-\eta$

The conversion rate, $\eta$, refers to the ratio of the contributed component derived from the annual discharged volume of a specific air pollutant to $\mathrm{PM}_{2.5}$ volume and this discharged volume itself. The mathematical expression for $\eta$ is given as Equation (4):

$$
\eta=\mathrm{V} . \mathrm{PM}_{2.5} \times \theta i / \mathrm{Dv}
$$

In the SD model system, $\eta$ is a very important auxiliary variable and is the key factor in the present study, which constructs a link between the annual discharged volume and the annual $\mathrm{PM}_{2.5}$ concentration in the quantitative relationship. The $\eta$ is based on the statistical data and does not have any actual physical and chemical significance; it is only used for the SD model.

6) The polluting GDP- $\mathrm{P}_{\mathrm{GDP}}$

In reality, not all economic activities cause heavy pollution; instead, some heavier polluting industries contribute to most of the air pollution. With this in mind, we proposed the concept of 'polluting GDP', which can be defined for those GDP generated specifically by the industries that discharge a major amount of air pollutants. In the SD simulation, by adjusting the primary, secondary and tertiary industries' GDP growth rate, the economic development could be influenced by the change in the industrial structure. In the process, we reduce the dirtier secondary industry ratio and increase the cleaner tertiary industry ratio to restrict the 'polluting GDP' while maintaining gross GDP growth. To achieve this, it is necessary to separate the 'polluting GDP' from the gross GDP, otherwise it would not be possible to analyse the environmental quality change after adjusting the industrial structure. The 'polluting GDP' equation is given as Equation (5):

$$
\mathrm{P}_{\mathrm{GDP}}=\alpha 1 \cdot \mathrm{GDP} 1+\alpha 2 \cdot \mathrm{GDP} 2+\alpha 3 \cdot \mathrm{GDP} 3
$$

where $\mathrm{P}_{\mathrm{GDP}}$ refers to the gross 'polluting GDP'. GDP1, GDP2 and GDP3 represent the city's primary, secondary and tertiary industry outputs, respectively. $\alpha 1, \alpha 2, \alpha 3$ represent different industrial weighted coefficients of 'polluting GDP', and they are a variable of time, but are not expected to fluctuate much in a certain period of time. To simplify the analysis, they are valued as constants. In the paper, we estimated the values of the three coefficients as $0.1,0.9$ and 0.1 , respectively, using the data from the Urban Statistical Yearbook. 
2 7) The sum of discharging a certain air pollutant $-E_{i}$

3 The sum of discharging a certain air pollutant, $E_{i}$, is an important transitional variable for

4 calculating the energy adjustment factor. This value is equal to the sum of discharging a certain air

5 pollutant caused by different types of energy consumption. The mathematical expression for $E_{i}$ is

6 given as Equation (6):

$7 \quad E_{i}=\sum_{j=1}^{n} E_{j}$

where $E$ is the energy consumption; $i$ is a specific air pollutant; $j$ is a specific energy resource 9 and $n$ is the number of energy resources.

8) The growth rate of a specific air pollutant $-r_{i}$

The growth rate of a specific air pollutant, $r_{i}$, caused by different kinds of energy consumption is an important transitional variable for calculating the energy adjustment factor. $r_{i}$ is a weighted average value of growth rates of different energy consumptions in a process of discharging a specific air pollutant. The mathematical expression for $r_{i}$ is given as Equation (7):

$$
r_{i}=\sum_{j=1}^{n} E_{j} r_{j} / E_{i}
$$

where $r$ is the growth rate, and the other symbols are the same as for the previous equations.

9) The energy adjustment factor-EF structure and before adjusting it to the base year. The mathematical expression for $E F$ is given as Equation (8):

$$
E F_{i}=1-\left(1+r_{i}\right) /\left(1+\lambda r_{G D P}\right)
$$
and $r_{\mathrm{GDP}}$ is the growth rate of GDP. 
10) The emission reduction factor $-R F$

The emission reduction factor, $R F$, refers to the reduction rate of a specific air pollutant's discharged volume based on the sum of stock and increment for reducing the total emissions. In other words, this reduction rate not only emphasises the reduction in the stock of discharged volume, but also on reducing the increment in discharged volume caused by the GDP growth. The mathematical expression for $R F$ is given as Equation (9):

$$
R F_{i}=r_{G D P}+\left(\sqrt[m]{1+r_{i . t \arg e t}}-1\right)+E F_{i}
$$

where $i$ stands for a specific air pollutant; $m$ is the year number from the base year to the planning target year and $r_{i . t a r g e t}$ is the accumulated reduction percentage that is normally a planning target for the Chinese government from the base year to the planning target year.

\section{Case study and results}

\subsection{An introduction to Wuhan city}

Wuhan city, the capital of Hubei province, China, is a metropolis located in the middle of China, with a population of 10.3 million people. In 2014, the region's GDP was 1006.9 billion Yuan and the annual concentrations of $\mathrm{PM}_{2.5}$ and $\mathrm{PM}_{10}$ were 82 and $113 \mu \mathrm{g} / \mathrm{m}^{3}$, respectively. On the one hand, to comply with the requirements of the most recent National $13^{\text {th }}$ Five-year Plan (FYP), the Wuhan Environmental Protection Bureau proposed stricter $\mathrm{PM}_{2.5}$ control objectives, i.e. the days of achieving air quality standards should be over $80 \%$ in a full year by 2020 , and the annual $\mathrm{PM}_{2.5}$ and $\mathrm{PM}_{10}$ concentrations should decrease by $40 \%$, with annual $\mathrm{PM}_{2.5}$ concentration decreasing to $42 \mu \mathrm{g} / \mathrm{m}^{3}$ by 2020 . On the other hand, Wuhan city is currently experiencing a critical period of economic development. On the basis of the city's social and economic development planning, the government wants to increase GDP to 2000 billion Yuan and emphasises that the economic growth rate should remain at $8.5 \%$ during the $13^{\text {th }}$ FYP. Trying to achieve both these objectives simultaneously is a massive challenge.

According to the meteorological data for Wuhan city over the past 50 years, the average annual temperature has remained at approximately $17^{\circ} \mathrm{C}$, with a slight upward trend. The average annual rainfall fluctuated between different years, but maintained approximately $1300 \mathrm{~mm}$. The 
average annual humidity was approximately $78 \%$, but in the past 20 years, this has slowly decreased. The average annual wind speed has remained at approximately $2 \mathrm{~m} / \mathrm{s}$ and for the past 20 years, there has been a slight downward trend (Qin, 2009; Shi et al., 2015). Generally, as a region, the changes seen in the climate over the past 15 years has been very small. In an economic-environmental system prediction process, the weather factors are considered stable and unchanging.

The chemical composition of $\mathrm{PM}_{2.5}$ or $\mathrm{PM}_{10}$ annual average concentrations and their external and internal source proportions are affected by many factors, including meteorology and human activities, as well as changes over time. Changes in these factors are random and independent of each other. In a one-year period, each factor has only a very slight influence on the overall result, which can be regarded as a stationary random process. Faced with a stationary random process, without further data, it can be considered acceptable that the sample statistics for 2014 represent the average results of chemical composition for a number of years.

Therefore, assuming a stable regional background, such as the annual average temperature, rainfall, wind speed and wind direction, the height of the atmospheric boundary layer, the proportion of source contribution from $\mathrm{PM}_{2.5}$ or $\mathrm{PM}_{10}$ inside or outside the city, and the chemical composition in source apportionment of $\mathrm{PM}_{2.5}$ and $\mathrm{PM}_{10}$ for the future 15 years, we established an SD model over the territorial extent of the whole city $\left(8494 \mathrm{~km}^{2}\right)$, with simulation for the period 2015-2030.

Four scenarios were set for the case study to obtain a relatively precise prediction: S1 Basic, S2 Moderate, S3 Enhanced and S4 Intense; these enabled to predict the different development situations and calculate the AEC and AECC results.

\subsection{Main data sources}

From Wuhan's research programme 'Main Environmental Problems and Counter Measures in Wuhan City', we obtained the main datasets for developing the SD model and predicting the AEC and AECC:

1) Wuhan statistical yearbook in 2014

2) White book of energy construction in 2014; 
13 ) Environmental protection planning in the period of $13^{\text {th }}$ FYP (2016-2020, first draft);

2 4) Technical report of the air pollutants' source apportionment of Wuhan city in 2014; and

3 5) Technical report of Wuhan city's air pollutant emissions inventory in 2014.

\section{$5 \quad 4.3$ The SD model test}

1) Reality test

The $\mathrm{PM}_{10}$ concentration and GDP were regarded as the reality test objects, excluding the $\mathrm{PM}_{2.5}$

8 concentration because the statistical data of $\mathrm{PM}_{2.5}$ concentration have only been recorded for two years since 2012. The steps undertaken for the reality test were as follows. First, check syntax, model check and units check are employed for the automatic detection of SD model via Vensim PLE. Second, the reality tests of $\mathrm{PM}_{10}$ concentration and GDP from year 2001 to 2013 were the main and important working steps. In the process of reality testing, the initial values in the model were based on the data from 2001. The values for three types of control variables, namely GDP growth rates, energy consumption rates and emission reduction factors, were based on the precedent data over 13 years.

The reality testing results indicated that the maximum error of GDP between the reality value and the simulated one was $-10.1 \%$, the minimum error $1.1 \%$, the mean error $-1.5 \%$, the correlation coefficient $\mathrm{r}=0.99$, the maximum error of $\mathrm{PM}_{10}$ concentration was $-14.5 \%$, the minimum error was $-0.8 \%$, the mean error was $0.36 \%$ and the correlation coefficient $r=0.80$. In short, the accuracy and correlation of GDP and $\mathrm{PM}_{10}$ predicted results were reasonable (Fig. 6).

\section{(a) Model reality test of GDP}

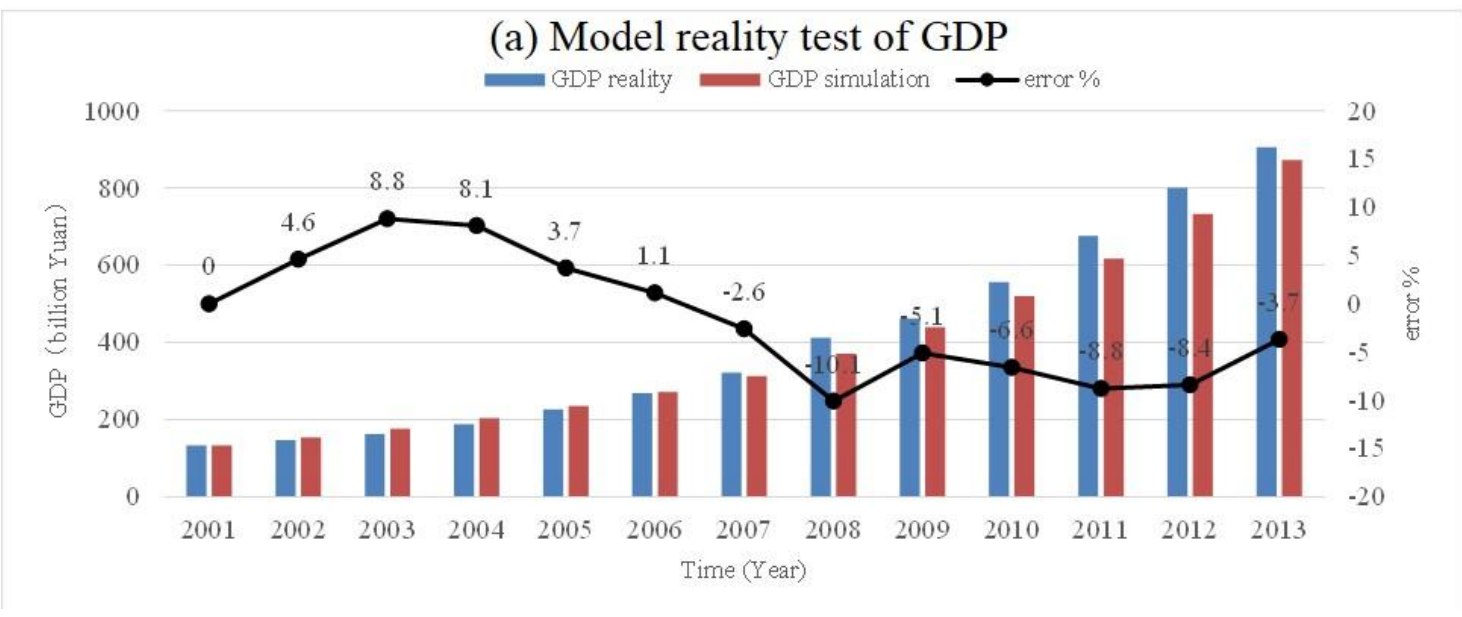


(b) Model reality test of $\mathrm{PM}_{10}$

PM10 reality $=$ PM10 simulation - error \%

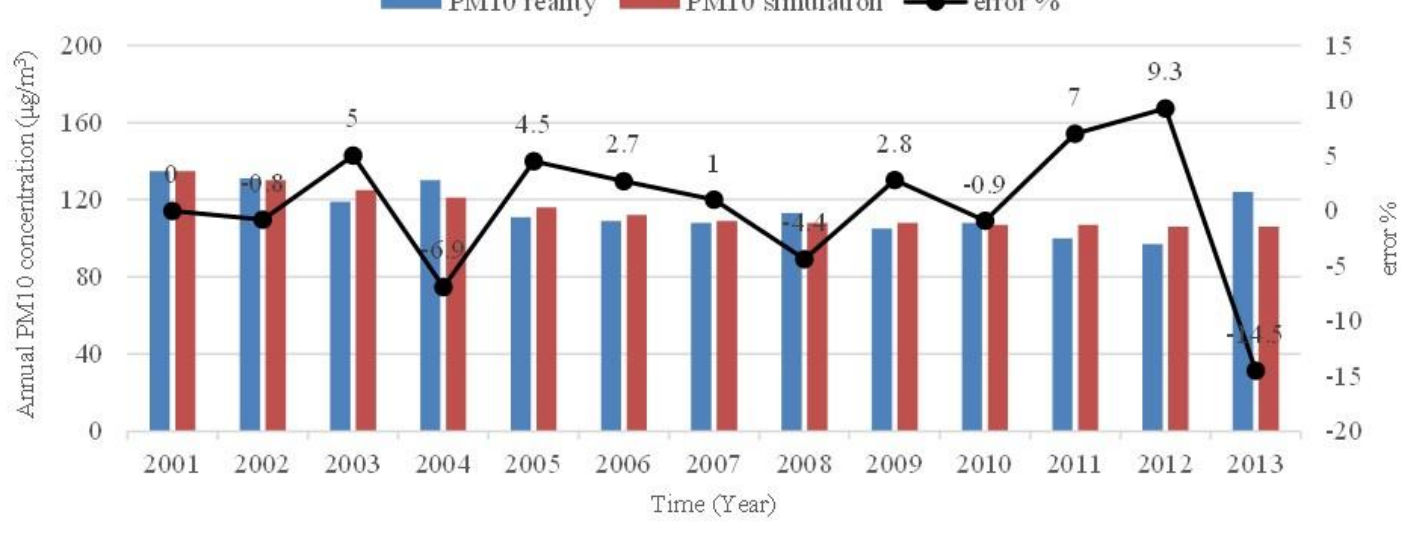

Fig.6 Model reality test of (a) GDP and (b) $\mathrm{PM}_{10}$.

2) Sensitivity analysis

The sensitivity analysis refers to an uncertainty analysis in which the degree of change in certain factors affects one or a set of key indicators from the view of quantitative analysis (Pannell, 1997).

The sensitivity test in the SD is aimed to assess the SD model's parameters settings or structure designs. Generally, the sensitivity test is widely used because the unknown variables usually overwhelm the known ones in the process of modelling. As known, the data obtained from project investigation and expert analysis are not always reliable for a research, but this can be mitigated through the sensitivity test. In the SD model, different parameters have different influence on a system; some are sensitive and some are not. The sensitive parameters are required to be verified and confirmed carefully and this is very important for modelling (Zhong et al, 2013).

In this model, there are 16 constants, among which the values of the energy consumption elasticity coefficient, the conversion rates of pollutants to PM2.5, the city's area and the height of boundary layer are based on the facts. However, the $\alpha 1, \alpha 2$, and $\alpha 3$ are estimated according to the related statistical data. These three values should be in a reasonable range in dealing with such a complex system. It would be interesting to know the simulation result if we change these values. The $\alpha 1$ is attributed to agriculture, and it is characterised to have a relative small scale and small influence. Therefore, we analyse only $\alpha 2$ and $\alpha 3$, and Table 2 summaries the simulation result. 
2 Table 2 Sensitivity analysis results for constant variables. Two tests are compared with the results from the S4

3 Intense scenario.

4

\begin{tabular}{l|l|l|l|l|l|l|l|l}
\hline & \multicolumn{3}{|c|}{$\alpha 2$} & \multicolumn{3}{c}{$\alpha 3$} \\
& Value & Change $(\%)$ & PM2.5 $\left(\mu \mathrm{g} / \mathrm{m}^{3}\right)$ & Change $\%)$ & Value & Change $(\%)$ & PM2.5( $\left(\mu \mathrm{g} / \mathrm{m}^{3}\right)$ & Change $(\%)$ \\
\hline Test1 & 0.7 & -23 & 22.1 & 3.2 & 0.15 & 50 & 22.7 & 6.0 \\
\hline Test2 & 0.8 & -12 & 21.7 & 1.4 & 0.2 & 100 & 23.9 & 11.6 \\
\hline S4 & 0.9 & 0 & 21.4 & 0 & 0.1 & 0 & 21.4 & 0 \\
\hline
\end{tabular}

In Table 2, the predicted $\mathrm{PM}_{2.5}$ concentration in 2030 changes to $22.1 \mu \mathrm{g} / \mathrm{m}^{3}$ and $21.7 \mu \mathrm{g} / \mathrm{m}^{3}$ respectively, when the $\alpha 2$, the polluting weighted coefficient, is decreased from 0.9 to 0.7 and 0.8 . Compared to $\mathrm{S} 4$, the decreasing range of $\alpha 2$ is -23 and $-12 \%$ and the change range of $\mathrm{PM}_{2.5}$ result in 3.2 and $1.4 \%$, respectively. In another group, the predicted $\mathrm{PM}_{2.5}$ concentrations in 2030 are 22.7 and $23.9 \mu \mathrm{g} / \mathrm{m}^{3}$, respectively, when the $\alpha 3$ is increased to 0.15 and 0.2 from 0.1 . Compared to S4, the increasing range of $\alpha 3$ is $50 \%$ and $100 \%$ and the change range of $\mathrm{PM}_{2.5}$ results in just $6.0 \%$ and $11.6 \%$, respectively.

From the sensitivity analysis results, we conclude that the change rate of the predicted $\mathrm{PM}_{2.5}$ concentration is significantly less than the adjustment range of $\alpha 2$ or $\alpha 3$ during a 15 -year simulation period. With this in mind, we believe that the SD model has a good stability, which meets the robustness requirement of a complex system.

\subsection{Input data}

Precise and credible predicted results depend on the actual and valid input variable data in the prediction process of the SD model. All the input data of level, control and constant variables in the SD model are based on the statistical data of 2014, as given in Tables 3, 4 and 5.

Table 3 Initial values in level variables.

\begin{tabular}{|c|c|c|c|}
\hline Level variables & Initial values & References & Notes \\
\hline GDP of primary industry & 35 billion Yuan & \multirow{3}{*}{$\begin{array}{l}\text { Environmental protection } 13^{\text {th }} \\
\text { FYP (first draft) }\end{array}$} & \\
\hline GDP of secondary industry & 478.5 billion Yuan & & \\
\hline GDP of tertiary industry & 493.3 billion Yuan & & \\
\hline Annual consumption of coal & $\begin{array}{l}34.54 \quad \text { million } \\
\text { tonnes }\end{array}$ & $\begin{array}{l}\text { White book of energy } \\
\text { construction in } 2014 \text { and the }\end{array}$ & \\
\hline
\end{tabular}




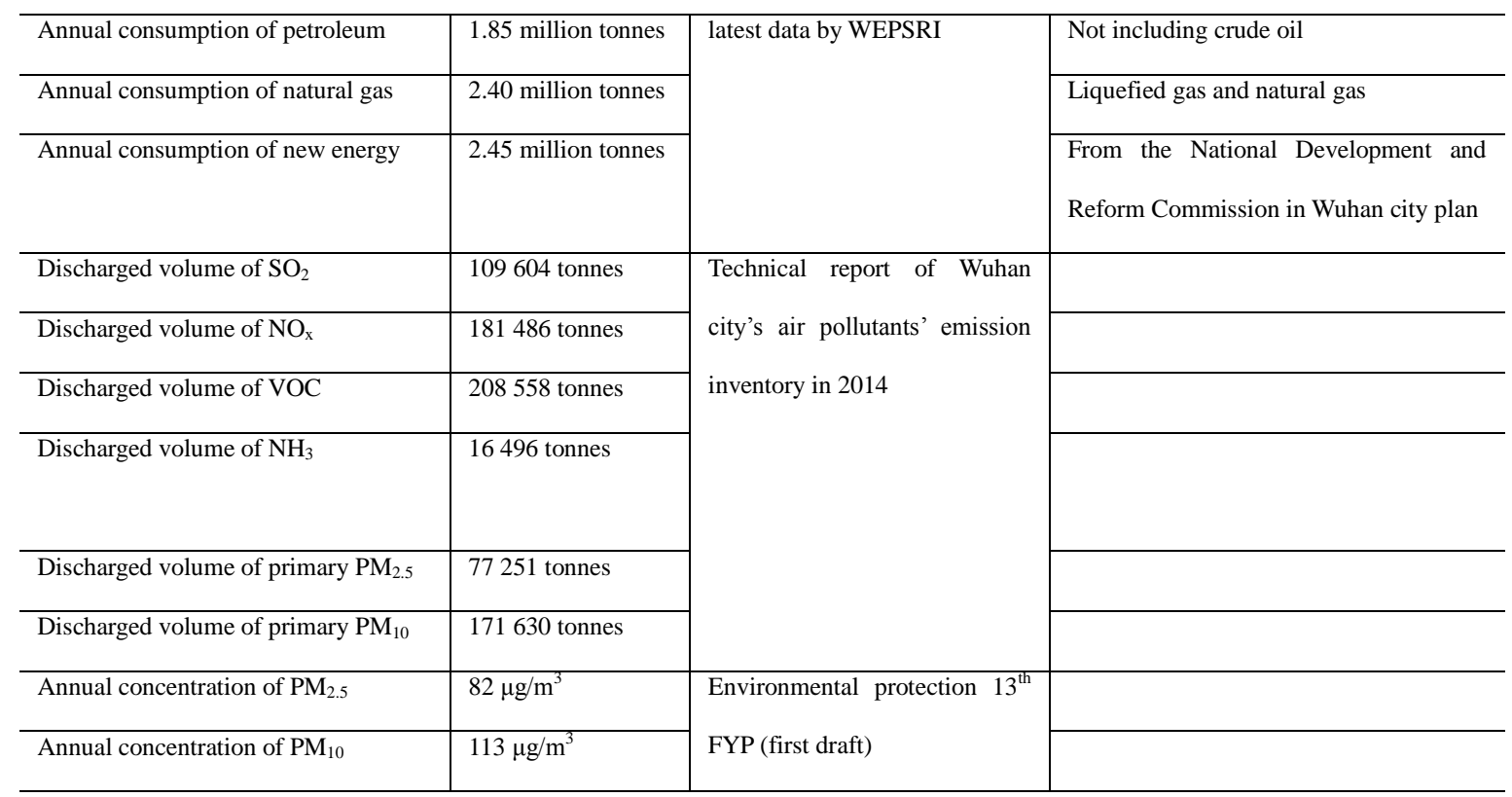

1

2

Table 4 Values of control variables.

\begin{tabular}{|c|c|c|c|c|c|c|c|c|c|}
\hline Control variables & \multicolumn{2}{|c|}{ S1 Basic } & \multicolumn{2}{|c|}{ S2 Moderate } & \multicolumn{2}{|c|}{ S3 Enhanced } & \multicolumn{2}{|c|}{ S4 Intense } & \multirow[t]{2}{*}{ References } \\
\hline Time periods & $\mathrm{T} 1$ & $\mathrm{~T} 2$ & T1 & $\mathrm{T} 2$ & T1 & $\mathrm{T} 2$ & T1 & $\mathrm{T} 2$ & \\
\hline Growth rate of primary industry & 0.04 & 0.03 & 0.04 & 0.03 & 0.035 & 0.03 & 0.03 & 0.025 & \multirow{3}{*}{$\begin{array}{l}\text { Environmental } \\
\text { protection } 13^{\text {th }} \text { FYP } \\
\text { (first draft) }\end{array}$} \\
\hline Growth rate of secondary industry & 0.065 & 0.04 & 0.055 & 0.04 & 0.045 & 0.03 & 0.035 & 0.03 & \\
\hline Growth rate of tertiary industry & 0.105 & 0.07 & 0.11 & 0.07 & 0.115 & 0.08 & 0.125 & 0.08 & \\
\hline Emission reduction factor of $\mathrm{SO}_{2}$ & 0.105 & 0.08 & 0.11 & 0.08 & 0.115 & 0.09 & 0.14 & 0.1 & \multirow{6}{*}{$\begin{array}{l}\text { Latest requirements } \\
\text { provided by WEPSRI }\end{array}$} \\
\hline Emission reduction factor of $\mathrm{NO}_{\mathrm{x}}$ & 0.08 & 0.07 & 0.09 & 0.08 & 0.1 & 0.08 & 0.105 & 0.08 & \\
\hline Emission reduction factor of VOC & 0.11 & 0.08 & 0.115 & 0.08 & 0.12 & 0.09 & 0.125 & 0.09 & \\
\hline Emission reduction factor of primary $\mathrm{PM}_{10}$ & 0.09 & 0.07 & 0.095 & 0.07 & 0.1 & 0.07 & 0.105 & 0.07 & \\
\hline Emission reduction factor of primary $\mathrm{PM}_{2.5}$ & 0.1 & 0.08 & 0.105 & 0.08 & 0.11 & 0.08 & 0.115 & 0.08 & \\
\hline Emission reduction factor of $\mathrm{NH}_{3}$ & 0.085 & 0.07 & 0.09 & 0.07 & 0.095 & 0.08 & 0.1 & 0.08 & \\
\hline Growth rate of coal & 0 & -0.005 & -0.01 & -0.01 & -0.02 & -0.015 & -0.03 & -0.02 & \multirow{4}{*}{$\begin{array}{l}\text { Latest requirements } \\
\text { provided by WEPSRI }\end{array}$} \\
\hline Growth rate of petroleum & 0.08 & 0.04 & 0.05 & 0.02 & 0.02 & 0.01 & 0.01 & 0.005 & \\
\hline Growth rate of natural gas & 0.16 & 0.1 & 0.18 & 0.11 & 0.2 & 0.12 & 0.22 & 0.13 & \\
\hline Growth rate of new energy & 0.14 & 0.1 & 0.17 & 0.11 & 0.2 & 0.12 & 0.25 & 0.13 & \\
\hline
\end{tabular}

3 Footnote: T1 stands for the period 2015-2020, T2 stands for 2021-2030.

4

Table 5 Values of constant variables.

\begin{tabular}{|c|c|c|c|}
\hline Variables & Values & References & Notes \\
\hline $\begin{array}{l}\text { Energy consumption elasticity } \\
\text { coefficient }\end{array}$ & 0.5 & $\begin{array}{l}\text { Environmental protection } 13^{\text {th }} \\
\text { Five Year plan (first draft) }\end{array}$ & \\
\hline$\alpha 1$ in polluting GDP & 0.1 & Wuhan statistical yearbook in & Estimated values, i.e. ratio coefficient of \\
\hline$\alpha 3$ in polluting GDP & 0.1 & 2014 & $\begin{array}{l}\text { polluting production output in a certain } \\
\text { industry and its industrial production. }\end{array}$ \\
\hline
\end{tabular}




\begin{tabular}{|c|c|c|c|}
\hline Contribution rate $\mathrm{SO}_{2}$ for $\mathrm{PM}_{2.5}$ & 0.21 & \multirow{10}{*}{$\begin{array}{l}\text { Technical report of Wuhan city's } \\
\text { air pollutants' source allotment in } \\
2014\end{array}$} & \\
\hline Contribution rate $\mathrm{NO}_{\mathrm{x}}$ for $\mathrm{PM}_{2.5}$ & 0.15 & & \\
\hline Contribution rate $\mathrm{VOC}$ for $\mathrm{PM}_{2.5}$ & 0.3 & & \\
\hline Contribution rate $\mathrm{NH}_{3}$ for $\mathrm{PM}_{2.5}$ & 0.1 & & \\
\hline $\begin{array}{l}\text { Contribution rate of primary } \\
\mathrm{PM}_{2.5}\end{array}$ & 0.15 & & \\
\hline $\begin{array}{l}\text { Contribution rate of primary } \\
\mathrm{PM}_{10}\end{array}$ & 0.21 & & \\
\hline Contribution rate $\mathrm{SO}_{2}$ for $\mathrm{PM}_{10}$ & 0.2 & & \\
\hline Contribution rate $\mathrm{NO}_{\mathrm{x}}$ for $\mathrm{PM}_{10}$ & 0.13 & & \\
\hline Contribution rate VOC for $\mathrm{PM}_{10}$ & 0.26 & & \\
\hline Contribution rate $\mathrm{NH}_{3}$ for $\mathrm{PM}_{10}$ & 0.08 & & \\
\hline City area & $8494 \mathrm{~km}^{2}$ & Network data & baike.baidu.com \\
\hline Height of boundary layer & $1000 \mathrm{~m}$ & No exact data & Used for computing \\
\hline
\end{tabular}

1

\subsection{Predicted results}

The predicted results showed that the annual $\mathrm{PM}_{2.5}$ concentration in year 2020 in $\mathrm{S} 1$ Basic, S2 Moderate, S3 Enhanced and S4 Intense are 66, 57, 49, and $42 \mu \mathrm{g} / \mathrm{m}^{3}$, respectively. These annual concentrations in year 2030 were calculated to be $45,35,25$, and $21 \mu \mathrm{g} / \mathrm{m}^{3}$, respectively. In the four scenarios, it is only in $\mathrm{S} 4$ Intense that the annual $\mathrm{PM}_{2.5}$ concentration can meet the latest requirement of environmental protection planning in Wuhan city. In S4, the annual concentration of $\mathrm{PM}_{2.5}$ scarcely reaches $35 \mu \mathrm{g} / \mathrm{m}^{3}$ when the simulation year is 2023.75 . This means that the following thresholds are all corresponding results of level variables (see in Fig. 7 except for the annual concentration of $\mathrm{PM}_{2.5}$ ) when simulation year is 2023.75 in S4 Intense:

1) Results of AEC in Wuhan city

The AEC results of $\mathrm{SO}_{2}, \mathrm{NO}_{\mathrm{x}}$, VOC, primary $\mathrm{PM}_{10}$, primary $\mathrm{PM}_{2.5}$ and $\mathrm{NH}_{3}$ constrained by GDP and $\mathrm{PM}_{2.5}$ on the basis of S4 simulation are $29679,87391,86643,64029,26336$, and 10 649 t, respectively (see Fig. 7a).

2) Thresholds of AECC in Wuhan city

(i) Thresholds of economic indicators ('recessive' component)

In S4, the thresholds of economic indicators, GDP and its production value of primary, secondary and tertiary industries are 1969, 45, 640.3, and 1283.9 billion Yuan, respectively (see Fig. 7b).

(ii) Thresholds of energy consumption ('recessive' component) 
1 In S4, the thresholds of energy consumption, including the consumption of coal, petroleum,

2 natural gas and new energy are the standard coal consumption of 27.28, 1.99, 12.33, and 14.92

3 million t, respectively (see Fig. 7c).

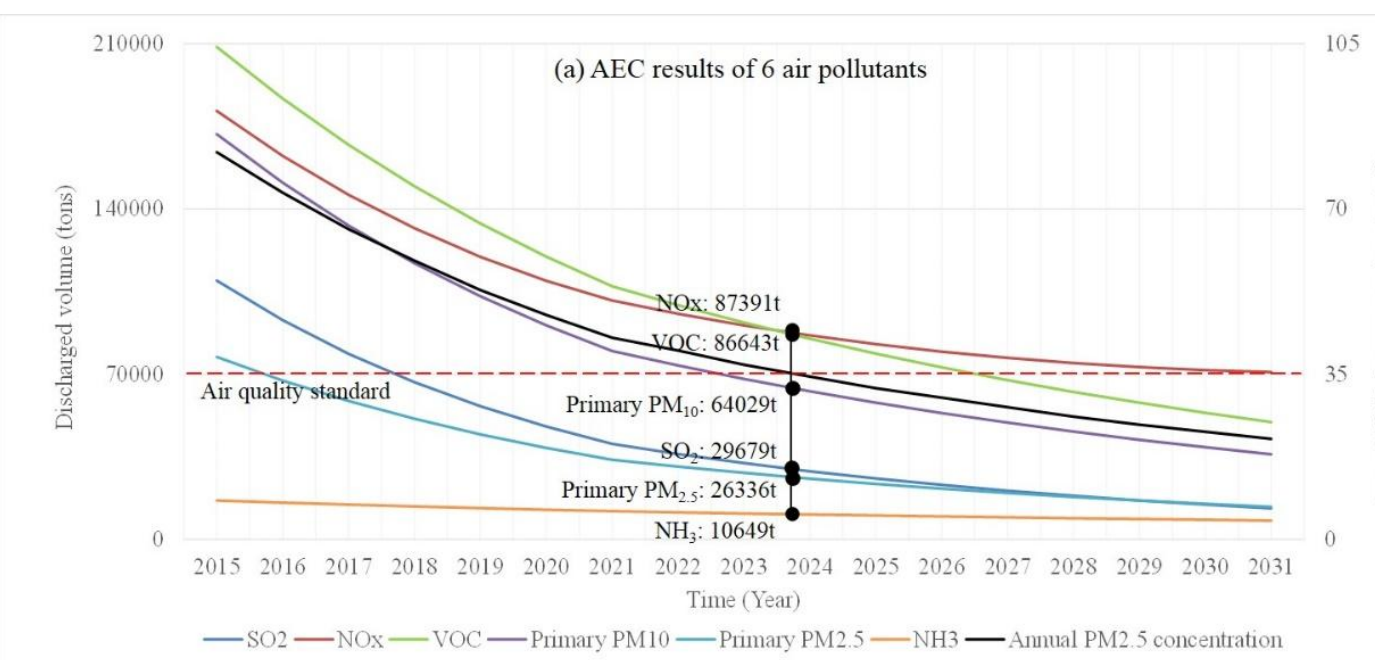

4

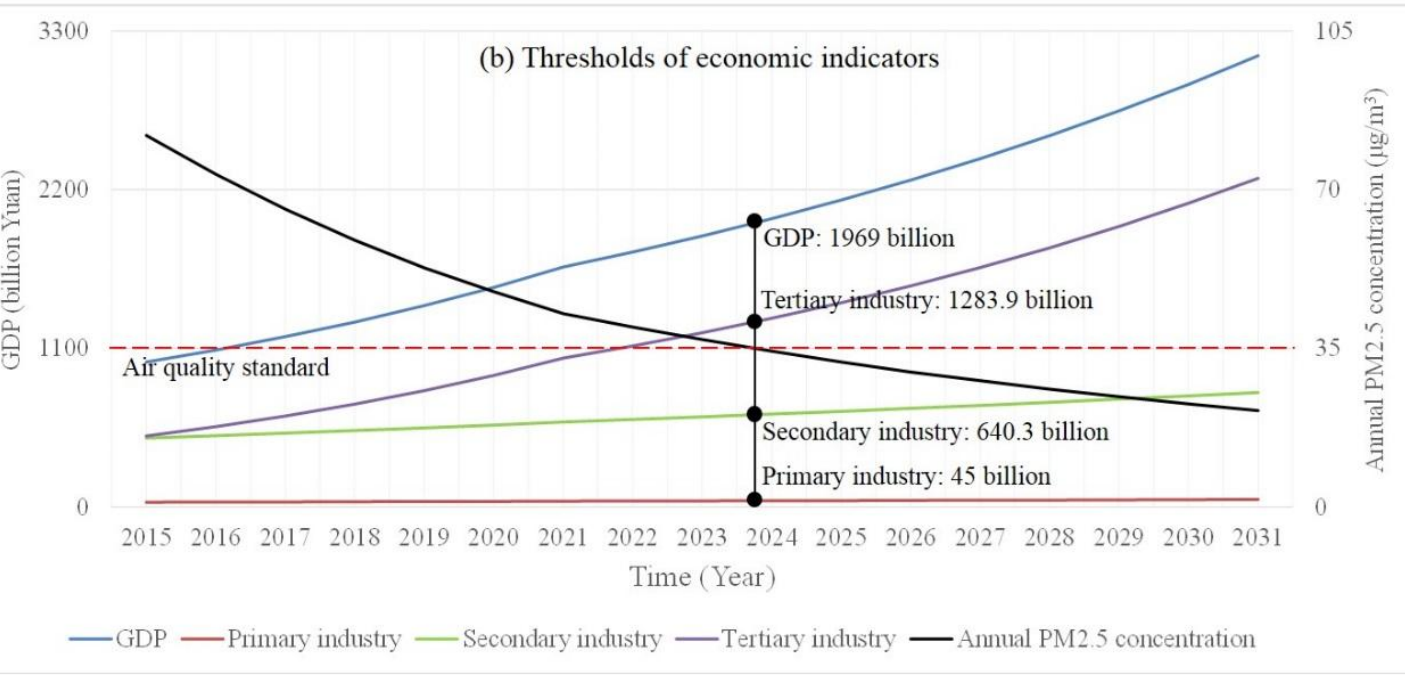

5

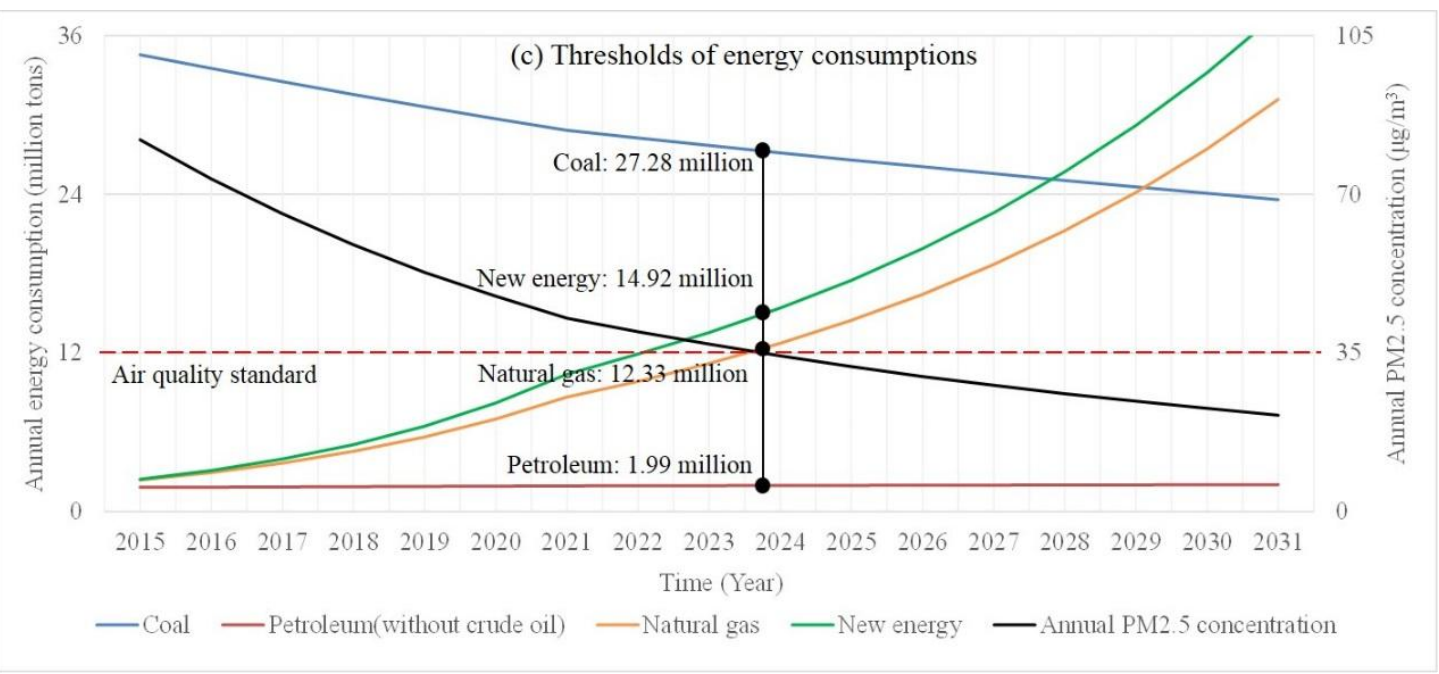

7 Fig.7 (a) AEC results of six air pollutants, (b) thresholds of economic indicators and (c) thresholds of energy 
consumptions. The results are marked by black dots when annual concentration of $\mathrm{PM}_{2.5}$ (black lines) reaches 35 $\mu \mathrm{g} / \mathrm{m}^{3}$ (the red dashed line) at simulated time 2023.75 .

(iii) Emission reduction thresholds ('expressive' component)

On the premise of keeping the composition of economic structure, energy and environmental protection level basically unchanged and GDP growth as normal, the predicted discharged volume of $\mathrm{SO}_{2}, \mathrm{NO}_{x}, \mathrm{VOC}$, primary $\mathrm{PM}_{10}$, primary $\mathrm{PM}_{2.5}$ and $\mathrm{NH}_{3}$ in 2023.75 beginning in 2015 were 213 278, 353 153, 405 832, 333974,150 322, and 32099 t, respectively, based on the data from 2014. After they were subtracted from the AEC results, the accumulative emission reduction thresholds were 183 599, 265762,319 189, 269 945, 123 986, and 21450 t, respectively. In other words, the six air pollutants would need to be reduced by 20 400, 29529,35 465, 29 994, 13 776, and $2383 \mathrm{t}$, respectively, each year based on the 2014 data (see Table 6).

Table 6 Emission reduction thresholds of AECC. To understand how the emission reduction thresholds should be calculated, predicted AES and S4 Intense AEC are also listed.

\begin{tabular}{ccccccc}
\hline Scenario & $\mathrm{SO}_{2}(\mathrm{t})$ & $\mathrm{NOx}(\mathrm{t})$ & $\mathrm{VOCs}(\mathrm{t})$ & Primary $\mathrm{PM}_{10}(\mathrm{t})$ & Primary $\mathrm{PM}_{2.5}(\mathrm{t})$ & $\mathrm{NH}_{3}(\mathrm{t})$ \\
\hline Predicted AES & 213278 & 353153 & 405832 & 333974 & 150322 & 32099 \\
\hline AEC of S4 & 29679 & 87391 & 86643 & 64029 & 26336 & 10649 \\
\hline $\begin{array}{c}\text { Accumulative emission } \\
\text { reduction thresholds }\end{array}$ & 183599 & 265762 & 319189 & 269945 & 123986 \\
\hline $\begin{array}{l}\text { Annual average emission } \\
\text { reduction thresholds }\end{array}$ & 20400 & 29529 & 35465 & 29994 & 2383 \\
\end{tabular}

\subsection{Discussion}

1) Credibility of the predicted results

The credibility of the predicted results depends on three aspects. First, the model logic is correct and its structure is reliable. Second, the initial values of level variables are accurate. Third, the control variables' parameter settings are reasonable. After the model structure and validity testing, input data proofreading and the reality testing and sensitivity analysis, the predicted results in the present case study are aligned with the development trends of the city with a high credibility. 
2) Limitations in traditional physicochemical methods

If there is a lack of data on the layouts and patterns of pollution sources and pollutant quantities, then the A-value method is an easy way of calculating the AEC in a region (MEP, 1991). To compare these two methods, we used the A-value method to estimate the $\mathrm{AEC}$ of $\mathrm{SO}_{2}$, $\mathrm{NO}_{\mathrm{x}}$ and $\mathrm{PM}_{10}$ in Wuhan city. However, the $\mathrm{VOC}$ and $\mathrm{NH}_{3}$ cannot be calculated using the A-value method. According to the $13^{\text {th }}$ FYP of environmental protection in Wuhan city, the development area belonging to type II category is $4926.5 \mathrm{~km}^{2}$ in size, with an occupation rate of $58 \%$ in the city; however, the limited development ecological area belonging to type I category is $3567.5 \mathrm{~km}^{2}$ in size, with an occupation rate of $42 \%$ in the city. The value of coefficient ' $\mathrm{A}$ ' ranges from 3.6 to 4.9 in the Hubei province, and from these values, it was calculated that the $\mathrm{AEC}$ of $\mathrm{SO}_{2}$ ranges from 143329 to 195069 t; $\mathrm{NO}_{\mathrm{x}}$ ranges from 132696 to 180614 t; and $\mathrm{PM}_{10}$ ranges from 190422 to $259185 \mathrm{t}$.

Therefore, the AEC results from the A-value method are higher than those calculated using the SD method. The AEC results from the A-value method are 4.8 6.5, 1.5 2 and 2.9 4.0 times the amount obtained from the $\mathrm{SD}$ method for $\mathrm{SO}_{2}, \mathrm{NO}_{\mathrm{x}}$ and $\mathrm{PM}_{10}$, respectively. This reveals that the AEC results constrained by GDP-PM 2.5 are much stricter than the results calculated from a single pollutant. In brief, the traditional AEC method has limitations when dealing with complex air pollution characterised as $\mathrm{PM}_{2.5}$.

\section{3) The same AEC results in different scenarios}

However, regardless of the degree of control in the model by control variables, the same reduction scale when assessing different pollutants can lead to the same pollutant AEC results appearing in different scenarios. In other words, the AEC is only related to polluted objects, the ambient air quality standard and a region's pollution dissipation capability.

\section{4) A further optimisation of the SD model}

The predicted results for the $\mathrm{PM}_{2.5}$ concentration may be relatively lower because the sum of proportion in five pollutants, $\mathrm{SO}_{2}, \mathrm{NO}_{\mathrm{x}}, \mathrm{VOC}, \mathrm{NH}_{3}$ and primary $\mathrm{PM}_{2.5}$ is only $91 \%$ of the total chemical composition. There is another unknown 9\%, and this has not been considered in the SD 
model. Therefore, it is necessary for future studies to determine ways of predicting $\mathrm{PM}_{2.5}$ concentrations with greater accuracy. With improvements in the development of monitoring ability of authorities, the conversion rate can be dynamically based on the updated source apportionment and emission inventory. This will ensure that the SD model is more reasonable and consistent with the reality. Moreover, more precise height of the atmospheric boundary layer could be obtained in cooperation with the meteorological department.

\section{5) Research prospect}

Deriving the AEC and AECC calculations in relation to compound air pollution, $\mathrm{PM}_{2.5}$, is a complicated task and a systematic project work that is unprecedented in China's history. Currently, this pollution was commonly ignored in the field of environmental protection. The calculation of environmental capacity and environmental carrying capacity is an essential work of top planning departments to improve environmental quality. This implies that besides the AEC and AECC, water and soil environmental capacity and their carrying capacities are also important for future research. At present, the related research about water is carried out at a fast pace (Cheng, 2010; Liu and Shao, 2015; Li et al., 2016). Generally, water capacity is calculated using the water quality analysis models based on hydrology data and the positions of discharging sources and quantities. However, this is a difficult work with a great amount of analysis and calculation and does not involve economic and social systems. Although both the theoretical and practical research has begun for the soil, these areas are facing many problems in China (Zhou et al., 2006). In relation to these, we hope to establish water and soil SD models for analysing their environmental capacity and carrying capacity by using macro statistical data that avoid simulating the complex physicochemical processes. We believe that this work has a great significance in remedying the vague, fragmented current situation and bridging some of the current gaps in the research of environmental capacity and its carrying capacity.

\section{Conclusions}

When researching environmental capacity and its carrying capacity, the influence of social economy cannot be excluded, something which the current physicochemical methods barely 
include; however, the SD method easily does. The SD method provides a powerful tool to establish quantitative links between different types of variables (such as emissions and the annual concentration of $\mathrm{PM}_{2.5}$ ) in the 'society-economy-environment' complex system. Compared to the physicochemical methods, using SD models does not require the inclusion of the physical and chemical processes of a complex system (e.g. the ecological massive system is too complex to determine all its internal contacts for researchers). A number of effective statistical and monitoring data help us to investigate the intrinsic logical relationship between complex objects from the outcome of things. This is a much simpler and more effective way than the physicochemical analysis methods.

The predicted results from the present study indicate that in the S4 Intense scenario, the annual $\mathrm{PM}_{2.5}$ concentration of Wuhan city reaches the target $\left(35 \mu \mathrm{g} / \mathrm{m}^{3}\right)$ at the simulated year 2023.75 . The corresponding AEC results of $\mathrm{SO}_{2}, \mathrm{NO}_{\mathrm{x}}$, VOC, primary $\mathrm{PM}_{10}$, primary $\mathrm{PM}_{2.5}$ and $\mathrm{NH}_{3}$ are 29 679, 87 391, 86 643, 64 029, 26 336, and 10649 t, respectively. The thresholds of economic indicators, GDP, and its production value of primary, secondary and tertiary industries are 1969, 45, 640.3, and 1283.9 billion Yuan, respectively. The thresholds of energy consumption, including coal, petroleum, natural gas and new energy are the standard coal consumption of 27.28, 1.99, 12.33, and 14.92 million tonnes, respectively. The 9-year accumulative emission reduction thresholds of six air pollutants are 183 599, 265 762, 319 189, 269 945, 123.986 and $21450 \mathrm{t}$, respectively. The environmental capacity results provide a reference for the Chinese government to formulate environmental protection planning, and the thresholds of carrying capacity help to determine the direction for the environmental-friendly social and economic development to occur.

\section{Acknowledgements}

The authors appreciate that Wuhan Environment Protection Science Research Institute (WEPSRI) favoured our creative research idea regarding the AEC and AECC, and provided us with the important chance to undertake the research as well as the financial support and key data support. The research was also supported by the National Science Foundation of China (NO.71171089). In addition, we would like to thank Yu Huang, the research director of WEPSRI, for her examination of the research results and Qing Liao for his help with the language. 


\section{References}

Arrow K., Bolin B., Costanza R., Dasgupta P., Folke C., Holling C.S., Jansson B.O., Levin S., Maler K.G., Perrings C., Pimentel D. 1995. Economic growth, carrying capacity and the Environment. Environ. Econ. 15, 91-95. http://dx.doi.org/10.1016/0921-8009(95)00059-3

Chen J.D., Wu Y.Y., Wen J., Cheng S.L., Wang J.L. 2016. Regional differences in China's fossil energy consumption: An analysis for the period 1997-2013. Journal of Cleaner Production. In Press, Accepted Manuscript, Available online 28 May 2016.

Cheng L. 2010. System dynamics model of Suzhou water resources carrying capacity and its application. Water. Sci. Eng. 3(2), 144-155. http://dx.doi.org/10.3882/j.issn.1674-2370.2010.02.003

Chateau P.A., Huang Y.C., Chen C.L., Chang Y.C. 2015. Integrated assessment of sustainable marine cage culture through system dynamics modeling. Ecol. Modell. 299. 140-146. http://dx.doi.org/10.1016/j.ecolmodel.2014.12.019

Djalalova. I., Monache. L.D., Wilczak. J. 2015. PM2.5 analog forecast and Kalman filter post-processing for the Community Multiscale Air Quality (CMAQ). Atmos. Environ. 119, 431-442. http://dx.doi.org/10.1016/j.atmosenv.2015.05.057

Feng.Y.Y., Chen S.Q., Zhang L.X. 2013. System dynamics modeling for urban energy consumption and $\mathrm{CO}_{2}$ emissions: A case study of Beijing, China. Ecol. Modell. 252. 44-52. http://dx.doi.org/10.1016/j.ecolmodel.2012.09.008

Furuya K. 2004. Environmental carrying capacity in an aquaculture ground of seaweeds and shellfish in Sanriku coast. Bull. Fish. Res. Agency. S1, 65-69.

Hu X.M., Ma Z.Q., Lin W.L., Zhang H.L., Hu J.L., Wang Y., Xu X.B., Fuentes J.D., Xue M. 2014. Impact of the Loess Plateau on the atmospheric boundary layer structure and air quality in the North China Plain: A case study. Sci. Total. Environ. 499. $228-237$. http://dx.doi.org/10.1016/j.scitotenv.2014.08.053

Huang R.J., Zhang Y.L., Bozzetti C., Ho K.F., Cao J.J., Han Y.M., Daellenbach K.R., Slowik J.G., Platt S.M., Canonaco F., Zotter P., Wolf R., Pieber S.M., Bruns E.A., Crippa M., Ciarelli G., Piazzalunga A., Schwikowski M., Abbaszade G., Schnelle-Kreis J., Zimmermann R., An Z., Szidat S., Baltensperger U., Haddad I., Prevot A.S.H. 2014. High secondary aerosol contribution to particulate pollution during haze events in China. Nature. 514. 218-222. http://dx.doi.org/10.1038/nature13774

Gao W., Hong B., Swaney D.P., Howarth R.W., Guo H.C. 2016. A system dynamics model for managing regional N inputs from human activities. Ecol. Modell. 332. 82-91. http://dx.doi.org/10.1016/j.ecolmodel.2015.12.001

Kiesewetter G., Schoepp W., Heyes C., Amann M. 2015. Modelling PM2.5 impact indicators in Europe: Health effects and legal compliance. Environ. Modell. Softw. 74. 201-211. http://dx.doi.org/10.1016/j.envsoft.2015.02.022

Li H.J. 2007. Research progress on the methods of the atmospheric environmental capacity calculation and total quantity control. Sichuan Environment. 26(1). 67-71 (in Chinese). http://dx.doi.org/10.14034/j.cnki.schj.2007.01.017

Li N., Yang H., Wang L.C., Huang X.J., Zeng C.F., Wu H., Ma X.X., Song X.T., Wei Y.N. 2016. Optimization of industry structure based on water environmental carrying capacity under uncertainty of the Huai River Basin within Shandong Province, China. J. Clean. Prod. 112. 4594-4604. http://dx.doi.org/10.1016/j.jclepro.2015.08.074

Liu B.X., Shao M.A. 2015. Modeling soil-water dynamics and soil- water carrying capacity for vegetation on the Loess Plateau, China. Agric. Water. Manage. 159. 176-184. http://dx.doi.org/10.1016/j.agwat.2015.06.019

Liu Z.R., Wang C.W., Hao J.M., Su B.L., Ma Y.L. 2009. Measuring environmental carrying capacity. Journal of Basic Science and Engineering. 17(1), 49-61 (in Chinese). http://dx.doi.org/10.16058/j.issn.1005-0930.2009.01.003

Li T.X., Cao S.Z., Fan D.L., Zhang Y.Q., Wang B.B., Zhao X.G., Leaderer B.P., Shen G.F., Zhang Y.W., Duan X.L. 2016. Household concentrations and personal exposure of PM2.5 among urban residents using different cooking fuels. Sci. Total Environ. 548-549. 6-12. http://dx.doi.org/10.1016/i.scitotenv.2016.01.038

Mao G.Z., Dai X., Wang Y., Guo J.H., Cheng X., Fang D.M., Song X.F., He Y.Y., Zhao P. 2013. Reducing carbon emissions in China: 
Industrial structural upgrade based on system dynamics. Energy Strategy Reviews. $2 . \quad 199-204$.

3 Martire S., Castellani V., Sala S. 2015. Carrying capacity assessment of forest resources: Enhancing environmental sustainability in energy production at local scale. Resour. Conserv. Recycl. 94. 11-20. http://dx.doi.org/10.1016/j.resconrec.2014.11.002

McKnight U.S., Finkel M. 2013. A system dynamics model for the screening-level long-term assessment of human health risks at contaminated sites. Envion. Modell. Softw. 40. 35-50. http://dx.doi.org/10.1016/j.envsoft.2012.07.007

Ministry of Environmental Protection of the people's republic of China (MEP). 2012. Ambient air quality standards (GB3095-2012). http://kjs.mep.gov.cn/hjbhbz/bzwb/dqhibh/dqhizlbz/201203/t20120302 224165.htm

Ministry of Environmental Protection of the people's republic of China (MEP). 1992. Technical methods for making local emission standards of air pollutants (GB/T 3840-91). http://kjs.mep.gov.cn/hjbhbz/bzwb/other/qt/199206/t19920601_67580.htm

Mondino E.B., Fabrizio E., Chiabrando R. 2014. A GIS tool for the land carrying capacity of large solar plants. Energy Procedia. 48. 1576-1585. http://dx.doi.org/10.1016/j.egypro.2014.02.178

Neuwirth C., Peck A., Simonovic S.P. 2015. Modeling structural change in spatial system dynamics: A Daisyworld example. Environ. Modell. Softw. 65. 30-40. http://dx.doi.org/10.1016/j.envsoft.2014.11.026

Oxley T., ApSimon H.M., de Nazelle A. 2015. Investigating the sensitivity of health benefits to focused PM2.5 emission abatement strategies. Environ. Modell. Softw. 74. 268-283. http://dx.doi.org/10.1016/j.envsoft.2015.07.011

Pannell, D. J. 1997. Sensitivity Analysis of Normative Economic Models: Theoretical Framework and Practical Strategies. Agricultural Economics 16: 139-152. http://dx.doi.org/10.1016/S0169-5150(96)01217-0.

Pui David Y.H., Chen S.C., Zuo Z.L. 2014. PM2.5 in China: Measurements, sources, visibility and health effects, and mitigation. Particuology. 13, 1-26. http://dx.doi.org/10.1016/j.partic.2013.11.001

Qin C.J. 2009. A study on the response of Wuhan climate under the background of global climate. Master's Thesis. College of Urban and environmental sciences, Central China Normal University (in Chinese).

Radzicki M.J., Taylor R.A. 1997. Introduction to System Dynamics. A Systems Approach to Understanding Complex Policy Issues. Retrieved 23.12.2013 from. http://www.systemdynamics.org/DL-IntroSysDyn/inside.htm.

Sahin O., Siems R.S., Stewart R.A., Porter M.G. 2016. Paradigm shift to enhanced water supply planning through augmented grids, scarcity pricing and adaptive factory water: A system dynamics approach. Environ. Modell. Softw. 75. 348-361. http://dx.doi.org/10.1016/j.envsoft.2014.05.018

Saveriades A. 2000. Establishing the social tourism carrying capacity for the tourist resorts of the east coast of the Republic of Cyprus. Tour. Manage. 21(2), 147-156.

Shi P.J., Zhang G.F., Kong F., Ye Q. 2015. Wind speed change regionalization in China (1961-2012). Advances in Climate Change

Research. 6, 151-158. http://dx.doi.org/10.1016/j.accre.2015.09.006

Vafa-Arani H., Jahani S., Dashti H., Heydari J., Moazen S. 2014. A system dynamics modeling for urban air pollution: A case study of

Tehran, Iran. Transportation Research Part D. 31. 21-36. http://dx.doi.org/10.1016/j.trd.2014.05.016

Wang C.W., Liu Z.R., Ge C.F. 2010. Theoretical research of environmental carrying capacity and its practice. China Environmental Science Press. Beijing. (in Chinese).

Wang T.X., Xu S.G.2015. Dynamic successive assessment method of water environment carrying capacity and its application. Ecol. Indic. 52. 134-146. http://dx.doi.org/10.1016/j.ecolind.2014.12.002

Wang J., Sun T.H., Li P.J., Li F.Y. 2005. Research progress on environmental carrying capacity. Chinese Journal of Applied Ecology. 16(4). 768-772 (in Chinese). http://dx.doi.org/10.13287/j.1001-9332.2005.0038

40 Wang Q.W., Zhao Z.Y., Shen N., Liu T.T. 2015. Have Chinese cities achieved the win-win between environmental protection and 
economic development? From the perspective of environmental efficiency. Ecol. Indic. 51. $151-158$. $\underline{\text { http://dx.doi.org/10.1016/j.ecolind.2014.07.022 }}$

Wang Q.F. 2009. System dynamics. Shanghai university of finance and economics press. Shanghai (in Chinese).

World Health Organization (WHO). Air quality guidelines for particulate matter, ozone, nitrogen dioxide and sulfur dioxide - Global update 2005 - Summary of risk assessment. http://www.who.int/phe/health_topics/outdoorair/outdoorair_aqg/en/

Xue W.B., Wang J.N., Niu H., Yang J.T., Han B.P., Lei Y., Chen H.L., Jiang C.L. 2013. Assessment of air quality improvement effect under the National Total Emission Control Program during the Twelfth National Five-Year Plan in China. Atmos. Environ. 68. 74-81. http://dx.doi.org/10.1016/j.atmosenv.2012.11.053

Yao L., Yang L.X., Yuan Q., Yan C., Dong C., Meng C.P., Sui X., Yang F., Lu Y.L., Wang W.X. 2016. Sources apportionment of PM 2.5 in a background site in the North China Plain. Sci. Total Environ. 541, 590-598. http://dx.doi.org/10.1016/j.scitotenv.2015.09.123

Ye W.H., Mei F.J., Guan B.R. 1992. Theory of environmental carrying capacity and its scientific significance. Res. Environ. Sci. 5(S1), $108-111$.

Yeh S.C., Wang C.A., Yu H.C. 2006. Simulation of soil erosion and nutrient impact using an integrated system dynamics model in a watershed in Taiwan. Environ. Modell. Softw. 21. 937-948. http://dx.doi.org/10.1016/j.envsoft.2005.04.005

Zhang Y.J., Hao J.F. 2016. The evaluation of environmental capacity: Evidence in Hunan province of China. Ecol. Indic. 60. 514-523. http://dx.doi.org/10.1016/j.ecolind.2015.07.028

Zhang X.H., Zhang R., Wu L.Q., Deng S.H., Lin L.L., Yu X.Y. 2013. The interactions among China's economic growth and its energy consumption and emissions during 1978-2007. Ecol. Indic. 24. 83-95. http://dx.doi.org/10.1016/j.ecolind.2012.06.004

Zhang X.H., Hu H., Zhang R., Deng S.H. 2014. Interactions between China's economy, energy and the air emissions and their policy implications. Renew Sustain Energy Rev. 38. 624-638. http://dx.doi.org/10.1016/j.rser.2014.07.002

Zhang. Y., Zhang. X., Wang. L.T., Zhang. Q., Duan. F.K. 2016. Application of WRF/Chem over East Asia: Part I. Model evaluation and inter comparison with MM5/CMAQ. Atmos. Envrion. 124, 285-300. http://dx.doi.org/10.1016/j.atmosenv.2015.07.022

Zeng W.H., Wang H.D., Xue J.Y., Ye W.H., Guan B.R. 1998. Theory of environment carrying capacity and its application of environmental planning on Meizhou Bay. China Environ. Sci. 18 (Suppl.). 70-73 (in Chinese).

Zeng W.H., Yang Y.M., Chen R.C.1991. Environmental carrying capacity: A key to the coordination of the development of population, resources and environment. China Population, Resources and Environment 1(2), 33-37 (in Chinese).

Zhong Y.G., Jia X.Q., Qian Y., et al. 2013. System Dynamics. Beijing: Science Press. (in Chinese).

Zhou J., Pei Z.P., Jin X.Y., Li X.Y. 2006. An overview for soil environmental capacity. Environ. Sci. Manage. 31(2), 74-76 (in Chinese).

Zhou X.H., Cao Z.Y., Ma Y.J., Wang L.P., Wu R.D., Wang W.X. 2016. Concentrations, correlations and chemical species of $\mathrm{PM}_{2.5} / \mathrm{PM}_{10}$ based on published data in China: Potential implications for the revised particulate standard. Chemosphere. 144, 518-526. $\underline{\text { http://dx.doi.org/10.1016/j.chemosphere.2015.09.003 }}$

\section{Appendix}

\section{The equations in the SD model system}

(001) Annual concentration of $\mathrm{PM}_{10}=$ INTEG (Increment in $\mathrm{PM}_{10}-$ Decrement in $\mathrm{PM}_{10}, 0.113$ ), Units: $\mathrm{mg} / \mathrm{m}^{3}$

(002) "Annual concentration of $\mathrm{PM}_{2.5}$ "= INTEG ("Increment in $\mathrm{PM}_{2.5}$ "-"Decrement of $\mathrm{PM}_{2.5}$ ", 0.082), Units: mg/m³

(003) Annual consumption of coal= INTEG (Increment of coal, 34.54), Units: million tonnes

(004) Annual consumption of natural gas= INTEG (Increment of natural gas, 2.4), Units: million tonnes

(005) Annual consumption of new energy= INTEG (Increment of new energy, 2.45), Units: million tonnes

(006) Annual consumption of petroleum= INTEG (Increment of petroleum, 1.85), Units: million tonnes 
(007) City area $=8.494 \mathrm{e}+009$, Units: $\mathrm{m}^{2}$

(008) City volume under boundary layer $=$ City area*Height of boundary layer, Units: $\mathrm{m}^{3}$

(009) "Contribution rate $\left(\mathrm{NH} 3\right.$ for $\left.\mathrm{PM}_{10}\right) "=0.08$, Units: Dmnl

(010) "Contribution rate $\left(\mathrm{NH} 3\right.$ for $\left.\mathrm{PM}_{2.5}\right) "=0.1$, Units: Dmnl

(011) "Contribution rate $\left(\mathrm{NOx}\right.$ for $\left.\mathrm{PM}_{10}\right) "=0.13$, Units: Dmnl

(012) "Contribution rate (NOx for $\left.\mathrm{PM}_{2.5}\right) "=0.15$, Units: Dmnl

(013) "Contribution rate $\left(\mathrm{SO} 2\right.$ for $\left.\mathrm{PM}_{10}\right) "=0.2$, Units: Dmnl

(014) "Contribution rate (SO2 for $\left.\mathrm{PM}_{2.5}\right) "=0.21$, Units: Dmnl

(015) "Contribution rate $\left(\mathrm{VOC}\right.$ for $\left.\mathrm{PM}_{10}\right) "=0.26$, Units: Dmnl

(016) "Contribution rate $\left(\mathrm{VOC}\right.$ for $\left.\mathrm{PM}_{2.5}\right)$ "= 0.3, Units: Dmnl

(017) Contribution rate of primary $\mathrm{PM}_{10}=0.21$, Units: Dmnl

(018) "Contribution rate of primary $\mathrm{PM}_{2.5}$ "= 0.15, Units: Dmnl

(019) "Conversion rate $\left(\mathrm{NH} 3\right.$ to $\left.\mathrm{PM}_{10}\right)$ "= $\mathrm{PM}_{10}$ volume*"Contribution rate (NH3 for $\left.\mathrm{PM}_{10}\right)$ "/Discharged volume of NH3, Units: Dmnl

(020) "Conversion rate (NH3 to $\left.\mathrm{PM}_{2.5}\right)$ "= "PM 2.5 volume"*"Contribution rate $\left(\mathrm{NH} 3\right.$ for $\left.\mathrm{PM}_{2.5}\right)$ "/Discharged volume of NH3, Units: Dmnl

(021) "Conversion rate $\left(\mathrm{NOx}\right.$ to $\left.\mathrm{PM}_{10}\right)$ "= $\mathrm{PM}_{10}$ volume*"Contribution rate (NOx for $\left.\mathrm{PM}_{10}\right)$ "/Discharged volume of NOx, Units: Dmnl

(022) "Conversion rate $\left(\mathrm{NOx}\right.$ to $\left.\mathrm{PM}_{2.5}\right)$ "= " $\mathrm{PM}_{2.5}$ volume"*"Contribution rate $\left(\mathrm{NOx}\right.$ for $\left.\mathrm{PM}_{2.5}\right)$ "/Discharged volume of NOx, Units: Dmnl

(023) "Conversion rate $\left(\mathrm{SO} 2\right.$ to $\left.\mathrm{PM}_{10}\right)$ "= $\mathrm{PM}_{10}$ volume*"Contribution rate (SO2 for $\left.\mathrm{PM}_{10}\right)$ "/Discharged volume of SO2, Units: Dmnl

(024) "Conversion rate (SO2 to $\left.\mathrm{PM}_{2.5}\right)$ "= "PM 2.5 volume"*"Contribution rate ( $\mathrm{SO} 2$ for $\mathrm{PM}_{2.5}$ )"/Discharged volume of SO2, Units: Dmnl

(025) "Conversion rate (VOC to $\left.\mathrm{PM}_{10}\right)$ "= $\mathrm{PM}_{10}$ volume*"Contribution rate (VOC for $\left.\mathrm{PM}_{10}\right)$ "/Discharged volume of VOC, Units: Dmnl

(026) "Conversion rate $\left(\mathrm{VOC}\right.$ to $\left.\mathrm{PM}_{2.5}\right)$ "= "PM 2.5 volume"*"Contribution rate $\left(\mathrm{VOC}\right.$ for $\left.\mathrm{PM}_{2.5}\right)$ "/Discharged volume of VOC, Units:

Dmnl

(027) Conversion rate of primary $\mathrm{PM}_{10}=\mathrm{PM}_{10}$ volume*Contribution rate of primary PM10/Discharged volume of primary PM10, Units:

Dmnl

(028) "Conversion rate of primary $\mathrm{PM}_{2.5}$ "= "PM 2.5 volume"*"Contribution rate of primary $\mathrm{PM}_{2.5}$ "/"Discharged volume of primary $\mathrm{PM}_{2.5}$ ",

Units: Dmnl

(029) Decrement of NH3= Discharged volume of NH3*Emission reduction factor of NH3, Units: tonne/Year

(031) Decrement of $\mathrm{PM}_{10}=$ Decrement of $\mathrm{NH} 3 *$ "Conversion rate $\left(\mathrm{NH} 3\right.$ to $\left.\mathrm{PM}_{10}\right)$ "* $1 \mathrm{e}+009 /$ City volume under boundary layer

+Decrement of $\mathrm{NOx} *$ "Conversion rate $\left(\mathrm{NOx}\right.$ to $\left.\mathrm{PM}_{10}\right) " * 1 \mathrm{e}+009 /$ City volume under boundary layer +Decrement of primary $\mathrm{PM}_{10} *$ Conversion rate of primary $\mathrm{PM}_{10} * 1 \mathrm{e}+009 /$ City volume under boundary layer +Decrement of $\mathrm{SO} 2 *$ Conversion rate ( $\mathrm{SO} 2$ to $\left.\mathrm{PM}_{10}\right) " * 1 \mathrm{e}+009 /$ City volume under boundary layer +Decrement of VOC*"Conversion rate $\left(\mathrm{VOC}\right.$ to $\left.\mathrm{PM}_{10}\right)$ "*1e+009/City volume under boundary layer, Units: $\mathrm{mg} /\left(\text { Year* }^{3}\right)^{3}$

(032) "Decrement of $\mathrm{PM}_{2.5}$ "=Decrement of $\mathrm{NH} 3 *$ "Conversion rate $\left(\mathrm{NH} 3 \text { to } \mathrm{PM}_{2.5}\right)^{\prime *} 1 \mathrm{e}+009 /$ City volume under boundary layer+ Decrement of NOx*"Conversion rate (NOx to $\left.\mathrm{PM}_{2.5}\right)$ "* $1 \mathrm{e}+009 /$ City volume under boundary layer+ Decrement of SO2*"Conversion rate $\left(\mathrm{SO} 2 \text { to } \mathrm{PM}_{2.5}\right)^{\prime \prime *} 1 \mathrm{e}+009 / \mathrm{City}$ volume under boundary layer+ Decrement of VOC*"Conversion rate $\left(\mathrm{VOC}\right.$ to $\left.\left.\mathrm{PM}_{2.5}\right)\right)^{* *} 1 \mathrm{e}+009 / \mathrm{City}$ volume under boundary layer+ "Decrement of primary PM2.5"*"Conversion rate of primary $\mathrm{PM}_{2.5}$ "*1e+009/City volume under boundary layer, Units: $\mathrm{mg} /\left(\mathrm{m}^{3} *\right.$ Year $)$

(033) Decrement of primary $\mathrm{PM}_{10}=$ Discharged volume of primary $\mathrm{PM}_{10}$ *Emission reduction factor of primary $\mathrm{PM}_{10}$, Units: tonne/Year

(034) "Decrement of primary $\mathrm{PM}_{2.5}$ "= "Discharged volume of primary $\mathrm{PM}_{2.5}$ "*"Emission reduction factor of primary $\mathrm{PM}_{2.5}$ ", Units: 
(035) Decrement of $\mathrm{SO} 2=$ Emission reduction factor of $\mathrm{SO} 2 *$ Discharged volume of SO2, Units: tonne/Year

(036) Decrement of VOC= Discharged volume of VOC*Emission reduction factor of VOC, Units: tonne/Year

(037) Discharged volume of NH3= INTEG (Increment of NH3-Decrement of NH3, 16496), Units: tonne

(038) Discharged volume of NOx= INTEG (Increment of NOx-Decrement of NOx, 181486), Units: tonne

(039) Discharged volume of primary $\mathrm{PM}_{10}=$ INTEG (Increment of primary $\mathrm{PM}_{10}$-Decrement of primary PM 10 , 171630), Units: tonne

(040) "Discharged volume of primary $\mathrm{PM}_{2.5}$ "= INTEG ("Increment of primary $\mathrm{PM}_{2.5}$ "-"Decrement of primary $\mathrm{PM}_{2.5}$ ", 77251 ), Units: tonne

(041) Discharged volume of SO2= INTEG (Increment of SO2-Decrement of SO2, 109604), Units: tonne

(042) Discharged volume of VOC= INTEG (Increment of VOC-Decrement of VOC,208558), Units: tonne

(043) Emission reduction factor of NH3=IF THEN ELSE(Time<2021, $0.1,0.08$ ),Units: 1/Year

(044) Emission reduction factor of NOx=IF THEN ELSE(Time<2021, 0.105, 0.08 )+Energy adjustment factor of NOx, Units: 1/Year

(045) Emission reduction factor of primary PM10=IF THEN ELSE(Time<2021, 0.105, 0.07 )+Energy adjustment factor of primary PM10, Units: 1/Year

(046) "Emission reduction factor of primary $\mathrm{PM}_{2.5}$ "=IF THEN ELSE(Time<2021, $\left.0.115,0.08\right)+$ "Energy adjustment factor of primary $\mathrm{PM}_{2.5}$ ", Units: 1/Year

(047) Emission reduction factor of SO2=IF THEN ELSE(Time<2021, 0.14, 0.1 )+Energy adjustment factor of SO2, Units: 1/Year (048) Emission reduction factor of VOC=IF THEN ELSE(Time<2021, 0.125, 0.09 )+Energy adjustment factor of VOC, Units: 1/Year

(049) Energy adjustment factor of NOx=1-(1+Growth rate of NOx $) /(1+$ Energy growth rate), Units: Dmnl

(050) Energy adjustment factor of primary $\mathrm{PM}_{10}=1-(1+$ Growth rate of particulate matter $) /(1+$ Energy growth rate), Units: Dmnl

(051) "Energy adjustment factor of primary $\mathrm{PM}_{2.5}$ "=1-(1+Growth rate of particulate matter)/(1+Energy growth rate), Units: Dmnl

(052) Energy adjustment factor of SO2=1-(1+Growth rate of coal)/(1+Energy growth rate), Units: Dmnl

(053) Energy adjustment factor of VOC=1-(1+Growth rate of petroleum)/(1+Energy growth rate), Units: Dmnl

(054) Energy consumption elasticity coefficient= 0.5, Units: Dmnl

(055) Energy consumption of discharging NOx=Annual consumption of coal+Annual consumption of natural gas+Annual consumption of petroleum, Units: million tonnes

(056) Energy consumption of discharging particulate matter= Annual consumption of coal+Annual consumption of petroleum, Units: million tonnes

(057) Energy growth rate= Energy consumption elasticity coefficient*Growth rate of GDP, Units: 1/Year

(058) FINAL TIME = 2031, Units: Year, The final time for the simulation.

(059) GDP=GDP of primary industry+GDP of secondary industry+GDP of tertiary industry, Units: billion Yuan

(060) GDP of primary industry= INTEG (Increment of primary industry, 35), Units: billion Yuan

(061) GDP of secondary industry= INTEG (Increment of secondary industry, 478.5), Units: billion Yuan

(062) GDP of tertiary industry= INTEG (Increment of tertiary industry, 493.3), Units: billion Yuan

(063) Growth rate of coal=IF THEN ELSE(Time<2021, -0.03, -0.02 ), Units: 1/Year

(064) Growth rate of GDP=Growth rate of primary industry*GDP of primary industry/GDP+Growth rate of secondary industry*GDP of secondary industry/GDP+Growth rate of tertiary industry*GDP of tertiary industry/GDP, Units: 1/Year

(065) Growth rate of natural gas=IF THEN ELSE(Time<2021, $0.22,0.13$ ), Units: 1/Year

(066) Growth rate of new energy=IF THEN ELSE(Time<2021, 0.25, 0.13 ), Units: 1/Year

(067) Growth rate of NOx= Growth rate of natural gas*Annual consumption of natural gas/Energy consumption of discharging NOx + Growth rate of coal*Annual consumption of coal/Energy consumption of discharging NOx +Growth rate of petroleum*Annual 
consumption of petroleum/Energy consumption of discharging NOx, Units: 1/Year

(068) Growth rate of particulate matter= Growth rate of coal*Annual consumption of coal/Energy consumption of discharging particulate matter +Growth rate of petroleum*Annual consumption of petroleum/Energy consumption of discharging particulate matter, Units: $1 /$ Year

(069) Growth rate of petroleum= IF THEN ELSE(Time<2021, 0.01, 0.005), Units: 1/Year

(070) Growth rate of primary industry= IF THEN ELSE(Time<2021, 0.03, 0.025), Units: 1/Year

(071) Growth rate of secondary industry= IF THEN ELSE(Time<2021, $0.035,0.03$ ), Units: 1/Year

(072) Growth rate of tertiary industry= IF THEN ELSE(Time<2021, $0.125,0.08)$, Units: 1/Year

(073) Height of boundary layer $=1000$, Units: $\mathrm{m}$

(074) Increment of coal= Growth rate of coal*Annual consumption of coal, Units: million tonnes/Year

(075) Increment of natural gas= Annual consumption of natural gas*Growth rate of natural gas, Units: million tonnes/Year

(076) Increment of new energy= Annual consumption of new energy*Growth rate of new energy, Units: million tonnes/Year

(077) Increment of NH3= Increment of pollutional GDP*Proportionality factor of NH3, Units: tonne/Year

(078) Increment of NOx=Energy adjustment factor of NOx*Increment of pollutional GDP*Proportionality factor of NOx, Units: tonne/Year

(079) Increment of petroleum= Annual consumption of petroleum*Growth rate of petroleum, Units: million tonnes/Year

(080) Increment of $\mathrm{PM}_{10}=$ Increment of $\mathrm{NH} 3 *$ "Conversion rate $\left(\mathrm{NH} 3\right.$ to $\left.\mathrm{PM}_{10}\right)$ ** 1 e+009/City volume under boundary layer+Increment of $\mathrm{NOx} *$ "Conversion rate $\left(\mathrm{NOx}\right.$ to $\left.\mathrm{PM}_{10}\right) " * 1 \mathrm{e}+009 /$ City volume under boundary layer+Increment of $\mathrm{SO} 2 * \mathrm{Conversion}$ rate $(\mathrm{SO} 2$ to $\left.\mathrm{PM}_{10}\right) * * 1$ e+009/City volume under boundary layer+Increment of VOC*"Conversion rate (VOC to PM 10 )"*1e+009/City volume under boundary layer+Increment of primary $\mathrm{PM}_{10} *$ Conversion rate of primary $\mathrm{PM}_{10} * 1 \mathrm{e}+009 /$ City volume under boundary layer, Units: $\left(\mathrm{mg} / \mathrm{m}^{3}\right) /$ Year

(081) "Increment of $\mathrm{PM}_{2.5}$ "=Increment of $\mathrm{NH} 3 *$ "Conversion rate $\left(\mathrm{NH} 3\right.$ to $\left.\mathrm{PM}_{2.5}\right)$ "*1e+009/City volume under boundary layer+Increment of $\mathrm{NOx} *$ "Conversion rate $\left(\mathrm{NOx}\right.$ to $\left.\mathrm{PM}_{2.5}\right) * * 1 \mathrm{e}+009 / \mathrm{City}$ volume under boundary layer+Increment of $\mathrm{SO} 2 *$ "Conversion rate $\left(\mathrm{SO} 2 \text { to } \mathrm{PM}_{2.5}\right)^{\prime *} 1 \mathrm{e}+009 /$ City volume under boundary layer+Increment of VOC*"Conversion rate (VOC to $\left.\mathrm{PM}_{2.5}\right) " * 1 \mathrm{e}+009 /$ City volume under boundary layer+"Increment of primary $\mathrm{PM}_{2.5}$ "*"Conversion rate of primary $\mathrm{PM} 2.5 * * 1 \mathrm{e}+009 / \mathrm{City}$ volume under boundary layer, Units: $\mathrm{mg} /\left(\mathrm{m}^{3} *\right.$ Year $)$

(082) Increment of polluting GDP $=0.1 *$ Increment of primary industry $+0.9 *$ Increment of secondary industry $+0.1 *$ Increment of tertiary industry, Units: billion Yuan/Year

(083) Increment of primary industry= GDP of primary industry*Growth rate of primary industry, Units: billion Yuan/Year

(084) Increment of primary $\mathrm{PM}_{10}=$ Energy adjustment factor of primary $\mathrm{PM}_{10} *$ Increment of pollutional GDP*Proportionality factor of primary $\mathrm{PM}_{10}$, Units: tonne/Year

(085) "Increment of primary $\mathrm{PM}_{2.5}$ "="Energy adjustment factor of primary $\mathrm{PM}_{2.5}$ "**Increment of pollutional GDP*"Proportionality factor of primary $\mathrm{PM}_{2.5}$, Units: tonne/Year

(086) Increment of secondary industry=GDP of secondary industry*Growth rate of secondary industry, Units: billion Yuan/Year

(087) Increment of SO2=Increment of pollutional GDP*Energy adjustment factor of SO2*Proportionality factor of SO2, Units: tonne/Year

(088) Increment of tertiary industry= GDP of tertiary industry*Growth rate of tertiary industry, Units: billion Yuan/Year

(089) Increment of VOC=Energy adjustment factor of VOC*Increment of pollutional GDP*Proportionality factor of VOC, Units: tonne/Year

(090) INITIAL TIME = 2015, Units: Year, The initial time for the simulation. 
1 (091) $\mathrm{PM}_{10}$ volume= Annual concentration of $\mathrm{PM}_{10} *$ City volume under boundary layer*1e-009, Units: tonne

2 (092) "PM 2.5 volume"="Annual concentration of $\mathrm{PM}_{2.5}$ "* City volume under boundary layer*1e-009, Units: tonne

3 (093) Polluting GDP $=0.1 * \mathrm{GDP}$ of primary industry $+0.9 * \mathrm{GDP}$ of secondary industry $+0.1 * \mathrm{GDP}$ of tertiary industry, Units: billion Yuan

4 (094) Proportionality factor of NH3= Discharged volume of NH3/Pollutional GDP, Units: tonne/billion Yuan

5 (095) Proportionality factor of NOx= Discharged volume of NOx/Pollutional GDP, Units: tonne/billion Yuan

6 (096) Proportionality factor of primary $\mathrm{PM}_{10}=$ Discharged volume of primary $\mathrm{PM}_{10} /$ Pollutional GDP, Units: tonne/billion Yuan

7 (097) "Proportionality factor of primary $\mathrm{PM}_{2.5}$ "="Discharged volume of primary $\mathrm{PM}_{2.5}$ "/Pollutional GDP, Units: tonne/billion Yuan

8 (098) Proportionality factor of SO2= Discharged volume of SO2/Pollutional GDP, Units: tonne/billion Yuan

9 (099) Proportionality factor of VOC= Discharged volume of VOC/Pollutional GDP, Units: tonne/billion Yuan

(100) SAVEPER = TIME STEP, Units: Year [0,?]. The frequency with which output is stored. 